\title{
That-trace effects and resumption - How Improper Movement can be repaired
}

\author{
Josef Bayer \& Martin Salzmann
}

July, 2012

\section{Outline}

The ungrammaticality that can be observed in subject extraction from that-clauses in English, known as the that-trace effect, has attracted much attention in generative grammar. Until today, most of the writing takes it for granted that the effect is directly connected to the placement or the role of the subject. In this article we will show that this is likely to be wrong. We will show on the basis of data from German that the that-trace effect emerges as the result of TOPIC EXTRACTION via the specifier of the complementizer that (SpecCP). Since subjects are very likely to serve as topics, and the grammar of English does not allow much variation in using other constituents as topics, it is understandable that the that-trace effect was taken to be a subject effect. The gist of our explanation of the that-trace effect is that constituents which have been moved to the topic position, more precisely to the position of an aboutness-topic, do not have a feature for contrastiveness, and that precisely such a feature is needed in long extraction to value a subfeature of the intermediate complementizer. ${ }^{1}$ This requirement allows essentially only constituents from the rhematic part of the clause to move long distance.

The article is organized as follows: Section 2 gives a short description of that-trace effects in English and comments on some more recent approaches. Section 3 turns to similar effects in German, pointing to means of circumventing the violation which are offered by the grammar of German. In this section it will be established that it is topic movement and not subject movement which gives rise to the observed violation. Making use of a feature of contrastivity, section 4 identifies the violation as related to what in previous research was seen as IMPROPER MOVEMENT. In section 5 the notorious problem of long extraction from zero-complementizer clauses will be addressed. Extending work that has been done on German, it will be argued there that also in English the construction is better analyzed as involving parenthetical insertion. In other words, what has been taken to be long subject extraction across a zero complementizer is in all likelihood short extraction into which a special parenthetical has been inserted. ${ }^{2}$ In section 6 we shift from the discussion of English and Standard German to a discussion of Zurich German relative clauses. Relative clauses in this dialect are of particular interest because they show a split between movement and resumption. Subjects and direct objects move and leave a trace whereas indirect objects and PP-objects etc. rely on resumption. Interestingly, this picture changes as soon as we are dealing with long relativization. In the latter case, even subject and direct object submit to resumption. On the basis of the extraction theory developed that far, this change receives a natural explanation, the reason being that the relative operator - unlike the wh-operator in questions - cannot value the contrast-feature in comp. The result is repair by means of resumption. It will be shown that a number of independent facts give support to the correctness of our explanation. Section 7 concludes the paper.

1 We will, of course, comment on the special role of contrastive topics.

2 Some of the results have been published in Bayer (2005). 


\section{That-trace effects in English}

The that-trace effect is a widely known constraint that holds in the grammar of many although perhaps not all - languages. In English it can best be seen in minimal pairs consisting of subject versus non-subject extraction.

(1) a. *Who 1 do you believe that tikes Mary?

b. Who 1 do you believe that Mary likes $t_{1}$ ?

The ungrammaticality of (1)a disappears when the wh-subject is extracted from a CP with a zero complementizer.

(2) Who 1 do you believe $t_{1}$ likes Mary?

It appears that the ungrammaticality arises from the adjacency between an overt $\mathrm{C}$ and the trace. In an early account, Chomsky and Lasnik (1977), examples like (1)a are ruled out by a filter, in this case the that-trace filter, which basically penalizes traces directly after that. In the government based theory to follow later in LGB, Chomsky (1981), the deviance of (1)a was taken to be due to failure of proper government, which affects the subject but not the object, a violation of the Empty Category Principle (ECP). Assuming for (2) extraction from a CP with a zero complementizer, it never became quite clear why (1)a and (2) differ sharply. Numerous technical solutions have been proposed which cannot be reviewed here but which in general have not overcome the impression of ad-hoc devices. As Pesetsky and Torrego (2001) say, the discrepancy

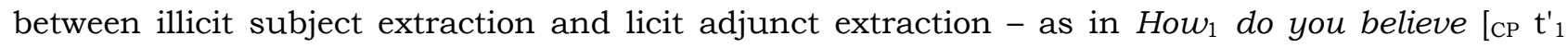
[ (that) [Mary crossed the river $\mathrm{t}_{1}$ ]]]? - could never be solved in the government-based accounts. Important insights in the nature of the that-t effect have been (i) that the effect is not limited to the subject trace, and (ii) that it can be suspended by intervening material. Consider locative inversion. As for (i), Bresnan (1994) observes that extraction of PPs which have undergone locative inversion invokes the same effect as subject extraction: ${ }^{3}$

(3) [In which villages $]_{1}$ do you believe (*that) $t_{1}$ can be found examples of this cuisine?

As for (ii), Bresnan (1977) and Culicover (1993) present examples which show that subject extraction ceases to be ungrammatical as soon as the trace of the subject is separated from the complementizer by intervening material. (4) is from Rizzi (1997) who attributes the observation to Bresnan (1977). (5) and (6) are taken from Culicover (1993: 558).

(4) a. *An amendment which 1 they say [that [ $t_{1}$ will be law next year]]

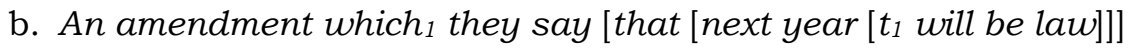

(5) This is the tree $\varnothing_{1}$ I think that just yesterday $t_{1}$ had resisted my shovel.

(6) Leslie is the person who ${ }_{1}$ I said that under no circumstances would t run for president.

Examples like those in (7) which involve expletive there to the immediate right of that can be found on the internet (cf. also Hartmann 2008: 93 for more examples):

3 There has been a long debate whether the locatives in Locative Inversion are subjects (at least at some point of the derivation). See Bruening (2010) for a recent overview and strong arguments against the subject status of the inverted locatives. 
(7) a. If, the creation now is in slavery of corruption, and it will be liberated to the glorious freedom of God, What do you believe that there is behind the veil?

b. Ok, but what do you think that there is in your music that puts it apart from the others, calling it "a little different"?

c. What do you think that there would be necessary to do with these people?

d. What do you think that there should be built?

www.skyscrapercity.com/...php/t-505003-p-2.html [07.01.2010]

The effect has become known as the ADVERB EFFECT (cf. Culicover 1993), and since Rizzi (1997) also as ANTI-ADJACENCY EFFECT. Rizzi \& Shlonsky (2007) do not consider cases of nonsubject extraction such as (3) and concentrate fully on the anti-adjacency effect. They propose a SUBJECT CRITERION, which turns the subject immobile once it has undergone checking in the specifier of a subject phrase (SubjP). Checking the subject in the specifier of SubjP leads to a FREEZING EFFECT. On a par with the scope immobilization that wh-elements undergo when moved to a wh-position, subjects are taken to be affected by freezing in a functionally defined subject position. Following the terminology of Rizzi's Criterion approach, the effect is referred to as an instance of CRITERIAL FREEZING. Subject-object asymmetries derive from the fact that there is a subject criterion, but not an object (or adjunct) criterion. However, languages have ways of extracting subjects. Rizzi and Shlonsky discuss different strategies such as the resumptive pronoun strategy, movement of larger chunks which contain the frozen subject (clausal piedpiping), and skipping strategies by which the freezing position is circumvented and the subject is extracted directly from a lower predicate-internal position. For zero-comp sentences like (2) they propose an analysis in which the embedded clause is headed by a nominal finiteness head Fin ${ }^{\circ}$ which bears silent phi-features such that Fin+Phi can satisfy the subject criterion. Fin, thus, basically acts as an expletive. This leaves the lexical subject who free to move. As an additional assumption, that is incompatible with Fin bearing phi-features so that the skipping strategy is not available in (1)a. ${ }^{4}$ In general it remains unclear (i) how adverbials such as next year, just yesterday, under no circumstances etc. can enjoy the privilege of satisfying the subject criterion, and (ii) why there should be a subject criterion in the first place. If one would not like to miss an explanation for cases like (3), the criterial freezing approach would require a "locative PP criterion". Rizzi \& Shlonsky (2006), in fact, extend the subject criterion approach in order to cover locative inversion. They notice that PP is not in the criterial subject position but rather in a higher (also criterial) topic-like position. Before it moves there it passes through a nominal Fin-head with a special locative feature the latter of which is said to be responsible for the satisfaction of the subject criterion, basically as in long-extraction across zero-comps. The ungrammaticality of (3) is argued to follow from the incompatibility of that with this skipping strategy, exactly as in (1)a. Whatever the merits of this amendment may be, it will not suffice to take care of the facts we will discuss in the next section. As we will show there, German provides evidence that extraction is inhibited from the high position while this high position can embrace subjects as well as nonsubjects, for instance, objects and high adverbs. ${ }^{5}$

4 One should critically add here that the approach is close to indistinguishable from Rizzi's (1990) approach in which the wh-subject in the intermediate SpecCP was taken to turn the zero complementizer into a proper head governor for the subject trace via spec-head agreement.

5 We hope to be realistic in our assumption that objects or adverbs like unfortunately would under no theoretical assumptions qualify for satisfaction of the subject criterion. 
Pesetsky \& Torrego (2001) offer an account of that-trace effects in terms of derivational economy. The burden is shifted to the timing of feature satisfaction in the course of the derivation. In their account, there is an unvalued T-feature $(u \mathrm{~T})$ in $\mathrm{C}$ which can be valued either by the complementizer that (which moves itself) or by the nominative subject. A wh-subject can value $u \mathrm{~T}$ and $u \mathrm{Wh}$ in $\mathrm{C}$ simultaneously whereas valuation of $u \mathrm{~T}$ by that and valuation of $u \mathrm{Wh}$ by the whsubject would require two steps. The less economical option is blocked. Object extraction as well as subject extraction across an intervening adverbial - the anti-adjacency effect - is fine because the wh-phrases are in both cases too far away from $\mathrm{C}$ to invoke competition between the two valuation procedures available. In Pesetsky \& Torrego's system, the role of the intervener is reduced to the establishment of non-locality. ${ }^{6}$ As far as we can see, it is not possible for phrases other than nominative DPs to value the $u$ T-feature in C. Like in Rizzi \& Shlonsky (2006) it would require extra machinery to make locative PPs responsible for the valuation of $u \mathrm{~T} .{ }^{7}$ Thus, although Pesetsky \& Torrego's theory is technically advanced and completely independent of the earlier ECP-account, it appears in fact to be narrowly tailored around the core facts of English that the ECP-account took care of. As we will see shortly, German data provide good reasons to look for an alternative.

\section{That-trace effects in German}

In the 1980s, the prevailing view was (i) that Standard German does not allow extraction from dass-CPs, but (ii) that such extraction is available in the Southern dialects and colloquial variants, and (iii) that in the latter case no that-trace effect can be observed. ${ }^{8}$ However, Featherston (2005) reports that in a magnitude estimation study the Comp-trace effect is "robustly active in the grammar of German“, although it is not as clearly delineated as in the empirical study of English by Cowart (1997). ${ }^{9}$ Similar results are reported in Kiziak (2010). We will shortly show that the degradation of subject extraction in German is unrelated to subjecthood but very much related to the highest clausal position. To prepare for this, let us, nevertheless, briefly remain with some observations on the role of subjects. Speakers for whom the ban on extraction from dass-CPs does not apply clearly allow subject extraction, but it is equally clear that this is not unconditionally the case. Consider (8):

$$
\begin{aligned}
& \text { ?? Wer1 glaubst du, dass ti kommt? } \\
& \text { who believe you that comes } \\
& \text { 'Who do you believe is coming?' }
\end{aligned}
$$

While (8) may not be unrescuable (in a sense we will make precise in (18) below), it is at variance with cases of subject extraction in which the subject could have been extracted from a lower position. (9) is such a case.

6 Locality in the sense of their constraint ATTRACT Closest X (ACX), cf. Pesetsky \& Torrego (2001: 369).

7 In their footnote 20, pp. 407-208, they suggest that such an extension could be achieved.

8 See Grewendorf (1988), Haider (1983) and also Müller (1995) as well as the dissenting voice of Fanselow (1987). See Featherston (2005) and Kiziak (2010) for a more recent overview.

9 We note here that Featherston finds a more general subject/object asymmetry. His experiments do not probe into the highest clausal position. Therefore, his results cannot be compared with ours directly. 
(9)

Wer glaubst du, dass 1933 in Hamburg Bürgermeister war?
who.Nom believe you that 1933 in Hamburg mayor was
'Who do you believe was the mayor of Hamburg in 1933?'

Anti-adjaceny predicts that there are two options for the location of the subject's trace which are non-offending. The expectation is that only extraction from the uppermost position would lead to a violation. ${ }^{10}$

(10) Wer glaubst $d u$, dass * $t_{1} 1933 \sqrt{ } t_{1}$ in Hamburg $\sqrt{ } t_{1}$ Bürgermeister war?

Assuming that (8) leaves only a single position as an option, and that this position is the highest in phrase structure, there is a first explanation of the contrast. Nevertheless, it remains unclear why examples like (8) still seem to be better than comparable examples in English. We will postpone this issue for the moment and will come back to it in (18).

\subsection{That-trace effects as topic-trace effects}

So far the German facts seem to be accounted for by Rizzi \& Shlonsky's (2007) subject criterion approach: Subject extraction is blocked once the subject moves into SpecSubjP as in (8). However, if as in (9), some other element satisfies the subject criterion (however this is done), subject extraction from a lower position is possible. We note first that this high position cannot be limited to nominative subjects. The restriction holds equally well for non-nominatives which take the highest role in the thematic hierarchy, e.g. dative experiencers.

$$
\begin{array}{llll}
\text { Wem } 1 & \text { glaubst } d u, \text { dass } & \text { ?*(beim Busfahren) } t_{1} \text { schlecht wird? } \\
\text { who.DAT believe you that at.the bus.riding } & \text { nauseous becomes }
\end{array}
$$

'Who do you think will become nauseous during the bus ride?'

Arguably, the PP beim Busfahren provides structure by which the parse of (11) allows the computation of a lower trace of the "quirky" dative subject wem. In the absence of this PP, only a single trace-position can be computed which is then the highest, it seems. The fact that nonnominatives invoke dass-t effects in German presents a problem for earlier accounts which took the subject trace to be licensed by virtue of complementizer agreement as in cases of compinflection (cf. Bayer 1984; Mayr 2010; Ackema \& Neeleman 2004). In German, datives do not undergo any kind of agreement with the finite verb or with the $\mathrm{C}$ that is associated with the finite verb. For this reason, one can be sure that the degradation stems exclusively from the high position from which the wh-item has been moved.

10 We make the plausible assumption that in the case of ambiguity the grammar computes only derivations which converge and leaves crashing derivations aside. Stranded quantifiers and the like restrict the choice between different trace positions. In fact, stranding is always better when the quantifier and therefore the trace is in a lower position.

(i) Wer glaubst du, dass (?*alles) 1933 ( $\sqrt{ }$ alles) in Hamburg ( $\sqrt{ }$ alles) in der Regierung war? who believe you that all 1933 in Hamburg in the government was

'Who all do you believe was 1933 in Hamburg in the government?'

We will return to similar cases shortly. 
Notice next that the dass-t effect appears with approximately the same strength in cases in which the subject - be it "straight" or "quirky" - cannot play a role. This can be seen in examples of sub-extraction as in was-für split. Once the extraction site is in the $v$ P's so-called nuclear scope, extraction is fine, but the result is degraded as soon as the extraction site has been moved to a high position above $v \mathrm{P}$. A reliable delimiter is the high discourse particle denn. One can show that only topic-like elements can appear to the left of denn. ${ }^{11}$ Although one can in principle scramble indefinites outside the scope of denn, the element was seen in (12)b can hardly leave the scrambled phrase was für Bücher.

a. Wası glaubst du, dass Peter denn [ $t_{1}$ für Bücher] kaufen würde? what believe you that Peter PART for books buy would 'What kind of books do you believe that Peter would buy?'

b.?*Was 1 glaubst $d u$, dass [ $t_{1}$ für Bücher] denn Peter kaufen würde? what believe you that for books PART Peter buy would 'What kind of books do you believe that Peter would buy?'

As Meinunger (2000) shows, similar examples can be found among other cases of splitting constructions. Since these sometimes involve quantifier splits, we need to be sure that there is no independent artifact that could prevent scrambling of the object over the subject. Let us therefore consider extraction from definite DPs. There is no doubt that definite DPs can undergo scrambling. Nevertheless, extraction from a scrambled DP is inhibited as seen in (13)b. ${ }^{12}$

11 Consider the contrast in (i) involving quantifiers taken from Bayer (to appear):

i. Hat denn in Venedig \{jeder / keiner\} einen Hund?

has DENN in Venice everybody nobody a dog

'Does \{everybody/nobody\} in Venice have a dog?'

ii. *Hat \{jeder / keiner\} denn in Venedig \{jeder / keiner\} einen Hund?

One reviewer finds b. "impeccable". This is unexpected because cursory internet searches reveal that there are hardly any occurrences of (fast) jeder (almost every), niemand (no one) nur XP (only XP) immediately preceding the particle denn in the relevant sense.

12 We are aware of a complication that we cannot explain so far. In German, DP-splitting in the topic position, as defined by discourse particles, tends to be degraded under local extraction, too i.e. extraction which does not cross an overt $\mathrm{C}$.

(i) Was2 würde der Peter denn t2 für Bücher kaufen? what would the Peter PRT for books buy

'What kind of books would Peter buy?'

(ii)??Was2 würde [t $t_{2}$ für Bücher] 1 denn der Peter t1 kaufen?

If the position above the modal particle is reached by scrambling, the deviance of (ii) and (12)b/(13)b can be explained as a freezing effect. If scrambling is taken not to involve movement (as e.g. in Fanselow 2001), the degradedness of these examples can be linked to the specificity of the DPs in question: Specific 


a. An Selbstmord glaube ich, dass der Oberarzt
about suicide believe I that the head-physician.NOM certainly
schon einmal [den Gedanken $\left.t_{1}\right]$ gehabt hat

already once the thought.ACC had had

'I believe that the head physician had certainly already once thought about suicide.'

\section{b. ?*An Selbstmord ${ }_{1}$ glaube ich, dass [den Gedanken $\left.t_{1}\right]_{2}$ der Oberarzt bestimmt schon} einmal to gehabt hat

Salzmann et al. (to appear) present the following example which shows that a dass- $t$ effect can be elicited by movement of an adverb.

Gestern 1 finde ich nicht, dass *(dort) $t_{1}$ hätte getanzt werden sollen.

Yesterday find I not that there had.suBJ danced become should

'As for yesterday, I don't think that people should have danced (there).'

Due to inversion of the finite verb hätte, there is no lower space to the right of dass from which the adverb gestern could have moved. Despite the fact that no DP or PP, let alone a subject, is involved, the example is exactly as degraded as a run-of-the-mill example of illicit subject extraction. In the presence of another adverb - in the example it is dort - the trace of gestern can be postulated in a lower position. As predicted by our theory, this improves the example to full grammaticality.

These data suggest that that-trace effects are independent of the subject or a subject criterion. Under the right constellations the effect can be replicated with scrambled objects and movable adverbs. A language like English, which lacks scrambling, fails to offer a more inclusive view of the phenomenon. In what follows, we will argue that so-called that-trace effects emerge if the sentence/aboutness topic undergoes long-distance movement. ${ }^{13} \mathrm{We}$ assume that there is a designated sentence topic position high in the German middle-field that is not reserved for a particular grammatical function such as subjects; rather, it can also be occupied by quirky subjects, scrambled objects and also adverbials or PPs of various kinds (typically those that can be used to set the stage for a given event). We will propose in section 4 below that long extraction from this position clashes with featural requirements of intermediate complementizers. ${ }^{14}$ Since the

DPs are often assumed to be islands for extraction. See Meinunger (2000) for extensive discussion of such cases and fn. 37 below.

13 Notice that there is also the broader notion of 'discourse topic'. There can be more than one discourse topic, and definite descriptions or pronominals referring to identified discourse referents may be distributed over various positions of a clause. 'Aboutness topics', on the other hand, appear to be formally defined. There is only one aboutness topic per sentence, and, as Frey $(2004 ; 2006)$ has shown, this topic seems to occupy a fixed high position in the clause which can be identified by its position relative to a high sentence adverb or certain modal particles. See also section 4 below.

14 Two precursors are worth mentioning here: (a) Bennis (1986: 225) suggests an Empty Presupposition Condition (EPC) which implies that extraction (not necessarily of a subject) takes place from a position which is preceded by presuppositional material. Since topics are typically part of the presupposition, the EPC translates into the claim that the highest position is occupied by some kind of topic, and that extraction must proceed from a position below the topic. (b) Meinunger (2000: 185) turns to the topic position directly. His Generalized Specificity Condition (GSC) states that topics are islands. Neither the EPC nor the GSC refer to C, but it would be surprising if these generalizations were independent of the that-t filter. 
subject often functions as the sentence topic, it will in many cases target the high position, which explains to some extent why that-trace effects have often been linked to subjecthood. But since the sentence topic position can also be occupied by other elements, the subject can remain low and undergo long movement in these cases. This is precisely what we observe in examples illustrating the anti-adjacency effect, cf. examples (5) through (11) above. In the absence of alternative constituents that would qualify as sentence topics as in (8), the subject is forced to move via that position: technically speaking, this implies that the functional head Top is equipped with an EPP feature. We assume that every sentence has a sentence/aboutness topic so that TopP is obligatory in every clause. ${ }^{15}$ Once the account of the that-t effect shifts from subjects to topics, we arrive at an explanation of the anti-adjacency effect that has been observed in English. In English, as we have seen, next year, yesterday, just yesterday, there, under no circumstances etc. are able to rescue the examples. Let us assume that these elements are potential topics and may occupy the topic position. ${ }^{16}$ The consequence for information structure is that idealiter the rest of the clause appears in the comment, and that extraction can proceed from the domain of the comment.

\subsection{The role of empty stage topics in German}

As we have seen, and as various researchers have observed before us, the dass-t effect in German is generally not as pronounced as the that-t effect appears to be in English. Therefore, some of the German examples have question marks while English examples have a plain asterisk. This means that there may be independent ways of saving German sentences from the dass-t filter that go beyond of what we have seen so far in terms of free word order. We see such special ways in the fact that German permits zero topics. A familiar example is (15).

$$
\begin{aligned}
& \text {... dass getanzt wurde } \\
& \text { that danced was } \\
& \text { that there was dancing' }
\end{aligned}
$$

In the past, this has often been taken to be a case of pro-drop, i.e. as involving a zero subject. As a matter of fact, however, an overt subject, namely es, is ungrammatical in (15). A grammatical solution that involves an overt element is one in which an adverb like $d a$ ('there') is inserted. 17

15 Since Reinhart (1981), a popular worry has been that quantified DPs such as every student cannot be topics because there is no entity or set which these DPs would refer to. Accordingly, Gilbert complained but not Every student complained would have a sentence/aboutness topic. This consequence violates elementary intuitions and must be built on some misanalysis. The solution lies in the fact that quantifiers operate on sets, and once the quantifier is stripped off, these sets make plausible topics. A sentence like Every student complained is then about a set of (discourse-relevant) students. See also Gundel (1999). The same applies to wh-phrases, as Koster (2003) points out, or negative indefinites (under no circumstances etc.) This insight squares with the general insight from formal semantics that quantified DPs need to be decomposed in one way or the other. See Erteschik-Shir (1999). Endriss and Hinterwimmer (2008) suggest analyzing indefinites as "indirect aboutness topics". Although they do not deal with quantified DPs proper, one can assume that the restrictive part of a quantified DP conforms to their notion of an indirect aboutness topic. We will return to decomposition in section 4 .

16 Cf. Salzmann (this volume) for arguments that topics can also target SpecTP in English, thereby satisfying the EPP.

17 See Bayer and Suchsland (1998) for discussion. 
Of course, da makes a perfect stage topic in the sense of Gundel (1974) and ErteschikShir (1997). The remarkable fact is that it can be missing in German. If we want to maintain that every declarative sentence has a sentence/aboutness topic (cf. also Kiss 2002), it follows that German allows a zero topic. (15) is then actually as in (17) where we identify VP with the comment.

$$
\text { dass [TорР [Тор } \varnothing] \text { [VP/Сомм getanzt wurde]] }
$$

The reason for the zero-topic option is not fully understood. We hypothesize that it has to do with the fact that in the syntax of German the functional head top itself is not overt either. ${ }^{18}$

If the language allows zero stage topics, it is predicted that there is very often a parse possible according to which the trace follows a topic. An example like (8) would then only be out

18 See Haider (2000) for discussion of word order in connection with functional heads. Various researchers (e.g. den Dikken 2007) observed a contrast in Dutch between sentences with and without verb inversion as in:

(i) a. ... dat gelachen werd (ok for many)
that laughed was
b. ... dat er gelachen werd (ok for everyone)
c. ... *dat werd gelachen (bad for everyone)
d. ... dat er werd gelachen (ok for many)

To find a similar contrast in German is hampered by a number of factors, but it appears as if the core constraints are not really different. German has a rule of inversion if two or more verbs are followed by the auxiliary haben. Consider (ii).

(ii) a. ... dass gelacht werden können hätte (strange for an independent and irrelevant reason)

that laughed become can had

b. ...??dass hätte gelacht werden können

c. ... dass damals hätte gelacht werden können hätte

Interestingly, once inversion has applied, i.e. the auxiliary precedes $\mathrm{VP}$, the position to the immediate right of $\mathrm{C}$ cannot remain empty. As seen in (iic), (iib) improves to full grammaticality as soon as some topical material is inserted between dass and hätte. One reviewer denies the degradedness of (iib). We would therefore like to refer the reader to an experimental investigation of constructions like (iib) in Salzmann, Häussler, Bader \& Bayer (to appear), in which the phonological adjacency of $\mathrm{C}$ and the finite verb turns out to be strongly disfavored by native speakers. 
as long as the trace was necessarily in the highest position following the complementizer. However, the parse seen in (18) would not involve an offending trace.

$$
\text { Wer } 1 \text { glaubst } d u \text {, dass [TорР [тор } \oslash][\text { ир/Сомм t1 kommt]]? }
$$

Presence or absence of a stage topic imposes a semantic difference. Assuming that the human comprehension system follows a maxim of grammatical trustworthiness, the parser would presumably postulate a silent topic and thus achieve a stage-level (eventive) interpretation.

If SpecTopP is not a possible landing site for certain phrases due to semantic reasons which prevent them from being potential topics, that-trace effect could still be absent, the reason being that an empty stage topic can be postulated. Consider amount phrases. Amounts are properties of properties. They cannot be picked up by a pronoun. ${ }^{19}$ Nevertheless, that (19)a is grammatical. We assume that the amount phrase has been extracted from a lower position than the topic position as seen in (19)b.

(19) a. Wie viel Champagner glaubst du, dass getrunken wurde? how much champagne believe you that drunk was 'How much champagne do you believe was drunk?'

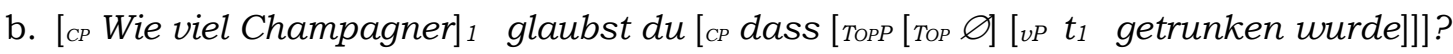

Assuming that there is the possibility of projecting an empty stage topic, we expect a contrast with respect to stage-level vs. individual-level predicates: stage-topics are only compatible with temporary states in the sense of Carlson (1977) and as seen in the contrast between There was a guy drunk (stage-level predicate) and *There was a guy intelligent (individual-level predicate). As Bennis (1986) had already noticed for Dutch, there is such a contrast in German. ${ }^{20}$

a. Wer glaubst du, dass $t_{1}$ betrunken ist?
who believe you that drunk is
'Who do you believe is drunk?'
b. ${ }^{\text {Wer }} 1$ glaubst du, dass $t_{1}$ blond ist?
who believe you that blond is
'Who do you believe is blond?'

The assumption is here that (20)b does not allow projection of a stage topic for semantic reasons, and that as a consequence the wh-operator wer itself has to take the topic position. ${ }^{21}$ Unless further and so far unindentified factors are involved, the unavailability of a stage topic -

19 Consider the ill-formedness of (i)

(i) * Wie viel Champagner glaubst du, dass $\{$ er/das $\}$ getrunken wurde?
how much champagne believe you that it/that drunk was
Intended: 'How much champagne do you believe was drunk?'

20 Note that these facts argue against PF-solutions to that-trace effects as in Ackema \& Neeleman (2004), Ackema (2010), and Kandybowicz (2006). Let us add that one of our German speaking reviewers claims to not get the contrast in (20) that we and others see here quite strongly.

21 Recall here what we said about operators in topic position in note 15 . In the next section we will discuss how the "topic part" of the wh-expression can be distinguished from the "operator part". Our proposal concerns only the topic part, of course. 
overt or covert - will render examples such as (20)b ungrammatical. Notice that a similar contrast arises with (21)a and (21)b.

(21) a. Wer glaubst du, dass geraucht hat? who believe you that smoked has

'Who do you believe has smoked?'

\section{b.??/لWer glaubst du, dass raucht?}

who believe you that smokes

i. 'Who do you believe is a smoker?'

ii. 'Who do you believe is smoking right now?'

The perfect tense in (21)a makes it plausible that there is a spatio-temporal location of a smoking event. Thus, invoking a stage topic is natural. The present tense in (21)b suggest the individual-level reading according to which persons should be identified who have the individuallevel property of being smokers. One should be sure that this reading is only suggested; it is not necessarily the only available one. To the extent that the present tense can be associated with a smoking event that holds at the time of the utterance, as suggested by the translation in (21)b.ii, the questions marks are likely to disappear.

To summarize at this point, we could show that the that-trace effect arises in German, too. As in English, this is the case when extraction takes place from the highest position below C. Subject extraction is often grammatical because the relatively free word order of German allows extraction from a lower position. Importantly, we could show that the effect has only an accidental connection with the subject. Long extraction of non-subjects yields the same type of violation if the non-subject is extracted from the highest clausal position below C. For this reason we suggested analyzing the that-trace effect as a constraint against the long extraction of a sentence/aboutness topic. We also identified another immunization strategy that seems to play a role in the syntax of German, namely postulation of a zero stage topic by which the trace of the extractee would be outside the topic region.

\section{That-trace as Improper Movement}

Now that we have established that long A'-movement from TopP is ungrammatical, we still need to explain where this restriction comes from. We will argue in this section that the constraint should be related to a contrastivity requirement on long A'-movement: only elements that are in principle contrastable can undergo such movement. We will argue that aboutness topics are inherently incompatible with this type of contrast so that as a consequence long A'movement of sentence topics is ruled out.

\subsection{Long $A^{6}$-movement requires contrastivity}

Movement to the "Vorfeld" of a German root clause may involve unstressed as well as stressed constituents. The clearest case of the former is provided by cases of movement of elements which cannot be stressed under any conditions. Examples are the pronouns es ('it'), which can be subject or object, and the generic subject pronoun man ('one').

a. Es hat geregnet.

it has rained

'It rained.' 
b. Es lief durch den Wald.

it ran through the woods

'It (e.g. the squirrel) ran through the woods.'

(23) a. Mandarf keinen Lärm machen.

one must no noise make

'One must not make any noise.'

b. Man wohnte in Höhlen.

one lived in caves

'People lived in caves.'

There is no reason to not assume movement to the clause-initial A'-position. The underlying structures show es and man in the highest position below C.

(24) a. dass es geregnet hat

b. dass es durch den Wald lief

c. dass man keinen Lärm machen darf

d. dass man in Höhlen wohnte

Movement of unstressed elements to preverbal position has been identified as „formal fronting“ (FF) by Fanselow (2002), Frey (2005) and Fanselow \& Lenertová (2011). FF takes the highest XP from TP and moves it to SpecFinP, an information-structurally neutral position in the left periphery. ${ }^{22}$ Next to this movement, there is "focus fronting" alias "contrastive fronting", i.e. movement of material that bears stress and can in principle be used contrastively. With 'contrastivity' we mean that the denotation of the constituent is a member of a set of potential alternatives. We assume that focus fronting targets a different specifier, i.e. SpecCP or SpecForceP, located above FinP. Examples appear in (25) and (26).

(25) a. Mein AUTO hat man gestohlen.

my car has one stolen

'It's my car which was stolen.'

b. ICH habe das behauptet.

I have this claimed

'It's me who claimed that.'

(26) a. dass man mein AUTO gestohlen hat

b. dass das ICH behauptet habe

22 The original generalization is from Bhatt's (1999) account of Kashmiri clause structure. Cf. Frey (2006) for cases of FF of object-es. Thus, in German the position in question cannot be limited to be related to the subject position. FF targets what Cardinaletti (2004) identifies as a "weak subject position". As can be expected, it includes also quirky subject-like elements like the dative in the following German example.

(i) Mir gefällt das Buch.

(derived from: (dass) mir das Buch gefällt)

me.DAT pleases the book.NOM

'I like the book.' 
As the embedded structure in (26), the material that undergoes focus fronting starts from a lower position as. An important aspect of this distinction is that XPs that do not belong to a potential set of semantic alternatives, must not participate in long-distance extraction.

a. ${ }^{*} \mathbf{s}_{1}$ glaube ich nicht, dass $t_{1}$ geregnet hat.

it believe I not that rained has

'I don't think it rained.'

b. ${ }^{*}$ Man $_{1}$ glaube ich nicht, dass $t_{1}$ gestern so viel Lärm hätte machen sollen. one believe I not that yesterday so much noise had make should 'I don't think one should have made so much noise yesterday.'

To see that the source of ungrammaticality is not conditioned by the phonological weakness of the extractee consider Frey's (2005) observation that a speaker-oriented adverb like leider ('unfortunately') cannot move long-distance despite its phonological strength. The reason seems to be that leider lacks potential alternatives. In (28), leider is grammatical with matrix clause construal but not with dependent-clause construal. In other words, leider cannot have moved long-distance. ${ }^{23}$

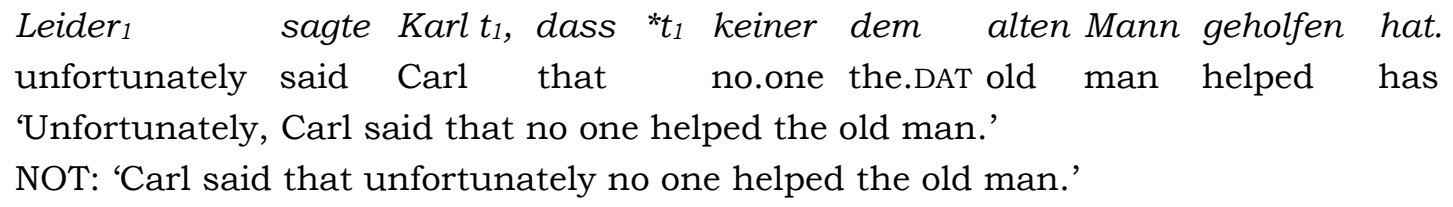

Bavarian, a German dialect which notoriously ignores the DouBlY-FILLED COMP FILTER $(\mathrm{DFCF})$, provides direct evidence for the source of the problem. Notice that in Bavarian constituents other than wh-phrases may move to SpecCP. (30) is taken from Lutz (1997).

\section{An Fünfer 1 daß-e to kriag häid-e ned g'moant. \\ a five that-I get had-I not thought}

'As for a grade five [which is almost the worst], I didn't think I would get one.'

The construction has become known as EMPHATIC TOPICALIZATION (ET), cf. Bayer (2001). As the name suggests, it is impossible to move phrases which cannot bear emphatic or potentially contrastive stress. Elements which resist long extraction resist ET. Since the weak pronouns es and man of Standard German are enclitics in Bavarian, the test should be made with the adverb leider. (30)a is grammatical but the ET-version in (30)b is impossible.

a. Dass-a leider ned kumma kõ hod-a g'sagt. that-he unfortunately not come.INF can has-he said 'Unfortunately he can't come, he said.'

b. *Leider 1 dass-a ti ned kumma kõ hod-a g'sagt.

\subsection{Sentence topics are non-contrastive (in the relevant sense)}

We can conclude that the complementizer dass imports a feature of contrast which can only be valued by a contrastable, i.e. potentially contrastive XP. As a caveat, the claim is not that

23 Exactly the same holds for English:

(i) *Unfortunately 1 , Carl said [ $t_{1}\left[\right.$ that [ $t_{1}$ no one helped the old man]]] 
movement to (and via) SpecCP automatically requires XP to be actually used contrastively. The claim is only that XP could in principle be used contrastively. ${ }^{24}$ Normally, contrastability of an XP requires that XP come from the comment. Let us ignore non-contrastable adverbs such as leider which are outside information structure in neither being topic nor (part of the) comment and return to the notion of topic. As has already been pointed out in section 3.1 above, the sentence topic is usually understood as the referent about which the sentence adds new information to the common ground shared by the interlocutors. The standard cases are referents which have been identified via a preceding discourse and make clear what the actual sentence is "about". At the moment of speaking, introduction or identification of the referent is not an issue any more. Conversation has made a leap by which the referent of the topic can be considered to have passed this stage. Competitors have ceased to play a role, so to say. As such it is at the moment of utterance non-contrastive. Assuming that the complementizer has an unvalued feature for contrastivity (uContrast) and that sentence topics are incompatible with the interpretable equivalent (iContrast), movement of the topic to SpecCP would be unable to value this feature. Before we delve deeper into this issue, a big caveat is required. The title of the current section could suggest that there aren't contrastive topics. As can be easily verified by the rich literature on information structure, this would be wrong, however. Consider the discourse in (30).

\section{A: Oswald killed the president. B: No. The FBI did.}

Both sentences are about the $\mathrm{x}$ such that $\mathrm{x}$ has killed the president, i.e. the assassin of the president. With the aim of yielding a true (or trustworthy) statement, speaker A has identified Oswald as the replacement of $\mathrm{x}$ while speaker B has identified the FBI as the replacement of $\mathrm{x}$. In this sense, the aboutness topic CAN be contrastive. ${ }^{25}$ But this "corrective" contrastivity must be distinguished from the comment-related contrastivity that drives discourse forward and that is a necessary precondition for long A'-movement. The clearest formal criterion for drawing a distinction is presumably provided by the opposition of presupposition and assertion. According

24 Unlike in Hungarian, focus in German materializes inside VP or in a VP-related lower functional FocP. Thus, the movement seen in ET or in contrastive fronting must not be confused with focus checking. By the time ET or contrastive fronting apply, focus checking has already applied. An early observation of this difference can be found in Behaghel (1932). ET/contrastive fronting target the highest position of a split $\mathrm{CP}$ and thus seem to be discourse-related.

25 One reviewer doubts that the contrastive (or corrective) DP the FBI is an aboutness topic. He or she infers this from the fact that it is focal. However, Krifka, to who this reviewer refers, says in (2008b: 267-268) explicitly, and in our view correctly, that they are "aboutness topic(s) that contains a focus, which is doing what focus always does, namely indicating an alternative". Our reviewer identifies in our example the killing of the president as the aboutness topic. But this would follow only if the aboutness topic is identified with old information. As Krifka points out, such identification is not justified. Consider his example

(i) A: What do your siblings do?

B: $\left[\text { My }[\text { SIster }]_{\text {Focus }}\right]_{\text {Topic }}[\text { studies MEDicine }]_{\text {Focus, }}$, and $\left[\text { my }[\text { BROther }]_{\text {Focus }}\right]_{\text {Topic }}$ is $[$ working on a FREIGHT ship] $]_{\text {Focus }}$

Although B's answer contains foci, it is about the siblings. So we have a case of "focus-in-topic". 
to Strawson (1964), the topic is presupposed and leads to presupposition failure when it does not refer. ${ }^{26}$ What we wish to maintain here is the fact that contrastivity is neutral with respect to the distinction topic/presupposition and non-topic/assertion. If so, contrastivity as such cannot be taken to be incompatible with topicality. In Erteschik-Shir's (2009) analysis, the topic is the top card on a stack of cards which belong to the common ground of speaker and hearer. Contrastive topics range over a given set from which one element is focused. ${ }^{27}$ As expected then, contrastive topics pattern with non-contrastive sentence topics in that they cannot undergo long $A^{\prime}$ movement; the following example illustrates this:

A: Wie geht es deinen Geschwistern? 'How are your brothers and sisters?'

B: ?*Meine Schwester glaube ich, dass zufrieden ist, my sister believe I that content is

mein Bruder habe ich gehört, dass einen neuen Job hat.

my brother have I heard that a new job has

'My sister I guess is quite happy; my brother I heard has a new job.'

Thus, when we speak of contrastivity in the next sections we mean the contrastivity that is induced by providing a particular new information (as opposed to some alternative information) via the assertion (rhematic part of the sentence). We call it for ease of reference "Contrast $t_{A}$ ".

\subsection{A new constraint on improper movement}

As we have already suggested in section 3.1 , see especially note 15 , topics can be distilled from quantified DPs. Speaking about dislocated quantified phrases, Gundel (1999) proposes that the actual topic in such a case is the entity that is quantified, i.e. the N-set, and not the whole quantified phrase. According to Heim (1982), decomposition into a restrictor and a quantifier part is independently motivated. While a QP like most (of the) girls or a wh-phrase like which (of the) girls is not as such referential and is therefore not fit to serve as a topic, its substructure which makes reference to a set of girls is able to do so. Thus one can integrate the intuition that sentences like Most (of the) girls like horses or Which (of the) girls like horses? are actually about a set of girls. The condition is that there is a file card on top of the common ground stack which refers to an appropriate set. Partitioning permits the $\mathrm{Q} /$ wh part to associate with the comment. Informally: As for (these) girls, \{most/which\} of them like horses. We submit that the partitioning is not only semantic, but also syntactic, i.e. operator and restriction are taken to be independent syntactic objects with their own features that may undergo independent movement and feature checking operations. We assume that the restriction part is PF-deficient and therefore has to undergo amalgamation with the operator at PF to be realized as one element. Importantly, amalgamation, being a PF-process, is subject to an adjacency requirement. What we propose here is in principle fully parallel to the analysis of negative indefinites in Penka (2007) where negative quantifiers like German kein ('no') are analyzed as consisting of an abstract negation plus a

26 To see this, consider the statement The king of France visited Konstanz University. It suffers from a presupposition failure because the sentence is about a non-existent entity. The sentence Konstanz University was visited by the king of France has a topic which refers successfully. By checking all the visitors of Konstanz University, once can see that the set contains no person like that. Thus, it can be determined that this sentence is simply wrong.

27 See also Krifka (2008a,b), for whom contrastive topics can be regarded as constituents whose denotations serve the function of both 'addressation' and 'delimitation'. 
positive indefinite that are unified at $\mathrm{PF}$. We will see shortly that the splitting analysis is important for the understanding of the contrast between local and long-distance A'-movement. For the time being, it is enough to see that the restrictive part can be on a par with definite descriptions and pronouns, certain PPs and certain adverbs in fulfilling the role of a sentence/aboutness topic, and that the topic is non-contrastive in the sense of Contrast ${ }_{\mathrm{A}}$, i.e. contrast which stems from the assertion and not from the presupposition.

Equipped with this, we are able to propose a constraint on extractability which explains the that-trace filter. Our proposal is that the sentence topic as the functionally determined element in SpecTopP is incompatible with a feature for Contrast $_{\mathrm{A}}$ that resides in $\mathrm{C}$. We assume the three clauses of (33). ${ }^{28}$

(33) i. iContrast is freely assigned to potentially contrastive constituents;

ii. the feature $i \mathrm{Op}$ - with $\mathrm{Op} \in\{\mathrm{wh}$, emp, foc $\}$ - is automatically contrastive (because it presupposes a set of semantic alternatives). The same holds for the uninterpretable equivalent on $\mathrm{C} /$ Force;

iii. phase-heads of category $\mathrm{C}$ (like that and dass) which are equipped with an edge-/EPPfeature that triggers successive-cyclic A'-movement bear $u$ Contrast.

There is exactly one aboutness topic per sentence, and we assume that this element must have been moved to a functionally defined position SpecTopP. ${ }^{29}$ Frequently, the subject moves to SpecTopP, but as has been amply demonstrated above, objects, adverbials, and base generated "expletive" elements like English there and German $d a$ or even empty stage topics can equally occupy SpecTopP.

By (33) we rule out topics as appearing in SpecCP: A topic, bearing a feature $i$ Top, will be able to move to SpecTopP valuing a corresponding feature $u$ Top. But when it moves on via SpecCP, the derivation eventually crashes because the subfeature $u$ Contrast on the intermediate $\mathrm{C}$ remains unvalued.

28 Unless we say otherwise, we always mean ContrastA. Contrast $t_{A}$ excludes Contrast a subfeature of a topic as in (31).

29 Of course, there can be more than one topic. The point is that only one of them serves as the aboutness topic. The others are topics by virtue of being discourse referents familiar from previous discourse. To the best of our knowledge, discourse topics can move to Top - actually a "topic field" - or stay in some scrambling position behind. Consider the optionality of movement in the second clause of the dialogue in (i) where denn delimits the topic field.

(i) A: Karl hat einen BMW gekauft. B: Hat er[den Wagen] denn [den Wagen] bar bezahlen können? Karl has a BMW bought has he the car PRT the car cash pay could A: 'Karl bought a BMW.' $\quad$ B: 'Could he pay the car in cash?'

Sentence B is invariably about Karl. So Karl is the aboutness topic; den Wagen, referring to the car Karl has bought, is a discourse topic. 
The relevant restriction on long topic movement can be described by the constraint in (34) which prevents the mixing of incompatible types of movement, namely topic movement and A'movement, which in this particular case involves contrastivity. As such, it is a minimalist version of IMPROPER MOVEMENT. ${ }^{30}$

\section{Constraint on A'-extraction}

In a structure $\left[\mathrm{CP}^{\circ}{ }^{\circ}{ }_{\text {Contrast }}\left[\mathrm{TopP} \mathrm{XP}\left[\mathrm{Top}^{\circ}[\ldots \mathrm{XP} \ldots]\right]\right]\right.$, movement of XP to SpecCP will lead to ungrammaticality.

\subsection{Wh-movement and splitting}

Let us now turn to wh-movement and consider here especially wh-topics. As proposed above, wh-phrases consist of two syntactically independent elements, an operator and a restriction that can be spelled out as one element only under adjacency at PF. The operator, henceforth $\mathrm{Op}$, has a feature $i \mathrm{Op}$ (and iContrast). The restriction lacks $i \mathrm{Op}$ and is neutral with respect to contrastivity. Thus, it can in principle have $i$ Top. We assume that questions are ForcePs. The operator is always directly inserted into the matrix scope position while the restriction originates in the theta-position and moves into the matrix clause. There are two configurations to consider: One where the restriction is the sentence topic and one where it is not. The derivation where the restriction does not function as sentence topic is as follows: The restriction starts out in an argument position in the embedded clause. Given (33)i, in the absence of an $i$ Top feature (and the presence of some other element that satisfies the respective feature on Top), the restriction can bear iContrast. Assuming that long-distance movement is triggered by an optional EPP/edge-feature on the intermediate $\mathrm{C}$, the restriction moves to SpecCP where it checks the feature $u$ Contrast of the complementizer. It then undergoes contrastive fronting to matrix ForceP to check $u$ Contrast. Finally, the operator is merged in a second specifier of Force, checking $u \mathrm{Op}$ of Force (in what follows, we ignore Agree processes involving phi- and Case-features for ease of representation; shared variables indicate shared values):

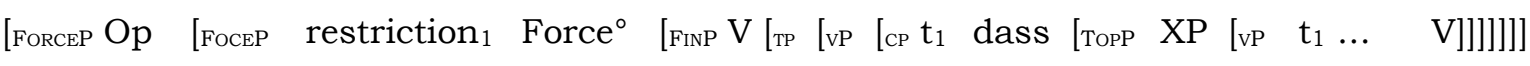

$$
\begin{aligned}
& i \mathrm{Op}[\mathrm{x}] \quad \text { iContrastly] } \quad u \mathrm{Op}[\mathrm{x}] \\
& \begin{array}{lll}
i \text { Contrast }[\mathrm{x}] & u \text { Contrast[y] } & u \text { Contrast[y] } \\
& \text { EPP } & \text { EPP }
\end{array}
\end{aligned}
$$

Since operator and restriction are adjacent, they can be amalgamated. ${ }^{31,32}$ Things are different if the restriction bears $i$ Top and is thus incompatible with iContrast. In that case it has

30 The ban on Improper Movement requires that types of movement must not be mixed. If A'-movement has applied to some DP, this DP cannot undergo A-movement afterwards, cf. Chomsky (1973) as a starting point. For a detailed treatment which adds scrambling to the inventory of movement types cf. Müller \& Sternefeld (1993), for a very recent implementation, cf. Müller (2012).

31 Note that our analysis has implications for the verb-second constraint: Normally it is assumed that only one constituent can appear in front of the finite verb. In our case, we actually have two constituents, at least at LF. Crucially, though, at PF only one element remains. This could imply that the verb-second constraint is actually a PF-constraint. Given the complexity of this issue we leave a discussion of the consequences for further research. The same question arises for negative indefinites. Cf. Penka (2007: 117-119) for discussion. But note that this assumption accords well with the observations in Meinunger (2006) that verb second movement is subject to prosodic restrictions.

32 This analysis may raise questions w.r.t. the Case morphology since in this derivation only the restriction is assigned Case while the operator remains Case-less. This seems to be at odds with the tendency in 
to move to SpecTopP. But then it is stuck there. It could in principle move to SpecCP to check the EPP-feature, but this would leave $u$ Contrast of $\mathrm{C}$ unchecked. ${ }^{33}$ Furthermore, without $i$ Contrast, the restriction also cannot be attracted to the matrix SpecForceP (to check $u$ Contrast). Consequently, the restriction remains in the embedded clause and therefore fails to be adjacent to Op so that the two cannot be unified. In that case, the derivation crashes at both LF and PF (while $u$ Contrast of Force can be valued by the operator, $u$ Contrast of $C$ remains unvalued): -34

\begin{tabular}{|c|c|c|c|c|}
\hline $\begin{array}{c}* \text { [Forcep Op } \quad[\text { Focep } \\
i \mathrm{Op}[\mathrm{x}]\end{array}$ & $\begin{array}{l}\text { Force }^{\circ} \text { [ FinP V [тр [ [ир [ст } \\
u \text { Op[x] }\end{array}$ & $\begin{array}{l}\text { restriction } \\
i \text { Top }[y]\end{array}$ & dass $\left[\begin{array}{ll}\text { TopP } & t_{1}\end{array}\right.$ & 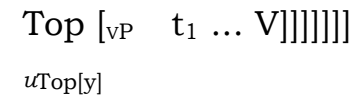 \\
\hline iContrast $[x]$ & $u$ Contrast $[x]$ & & $u$ Contrast [ ] & \\
\hline & EPP & & EPP & EPP \\
\hline
\end{tabular}

This account predicts the existence of a repair strategy: The restriction can remain below if it is realized by means of a resumptive pronoun as in the following example: 35

German for Case morphology to be only visible on the operator and much less so on the restriction. Note though, that the operator is not simply to be equated with D and the restriction with NP. Rather, we assume that the restriction is a full DP so that the case assigned to it will eventually be realized on the spelled-out D-part that results after amalgamation.

33 Note that while the EPP-features on heads like Force, Fin or Top basically function as movement diacritics that indicate that feature valuation must be followed by internal merge, the EPP-feature on intermediate $\mathrm{C}$-heads is independent of $u$ Contrast, it just requires that some constituent is moved to the edge domain of $\mathrm{C}$, checking/valuation of unvalued features (such as $u$ Contrast) is not a precondition. This difference should be borne in mind given that we make no terminological distinction.

34 Even if one were to allow for the possibility that the restriction undergoes formal fronting to the matrix FinP, $u$ Contrast of the intermediate $\mathrm{C}$ would still remain unvalued. Additionally, one has to avoid that the operator starts out in the intermediate SpecCP as it could check $u$ Contrast of $\mathrm{C}$ so that the derivation should converge, contrary to fact. We will provisionally assume that for semantic reasons the operator can only be inserted into positions where it can check its $u$ Op-feature (furthermore, it seems reasonable to assume that edge-features on phase-heads can only be checked by means of internal merge).

35 Resumption under wh-movement is strongly degraded in German (cf. also section 6.7 below) but somewhat more acceptable in English. Resumptives are marginally available for object extraction as well. This may seem surprising since topicality cannot be at stake. Rather, what seems to be the case is that base-generation is an independent option which is optional for objects but necessary for subjects to avoid a that-trace effect. The fact that one reviewer finds (37) deviant is not surprising. Repair by resumption avoids the that-t effect but may induce other sacrifices; it is well-known that resumptive pronouns in English are not a fully grammatical device (but rather should be classified as so-called intrusive resumptives, cf. Chao \& Sells 1983). Nevertheless, it cannot be denied that resumption is used to avoid that-trace violations. Witness the following examples.

(i) Who do you think that he/she is the best Popstar Dancer?

http://forums.denden.co.uk/viewtopic.php?f=1\&t=205917\&start $=25$ [05.05.2012] 
Who did you say that he will come?

Such cases obtain if the intermediate $\mathrm{C}$ does not have a movement-triggering EPP/edgefeature. ${ }^{36}$ As a consequence, it also lacks $u$ Contrast. The operator is again directly merged in ForceP and checks $u O p$ (and $u$ Contrast). The resumptive pronoun then checks $i$ Top in the embedded clause. With the abstract restriction PERSON (with who $=$ wh+PERSON), such a derivation would be impossible because the restrictor PERSON would not be able to amalgamate with Op:

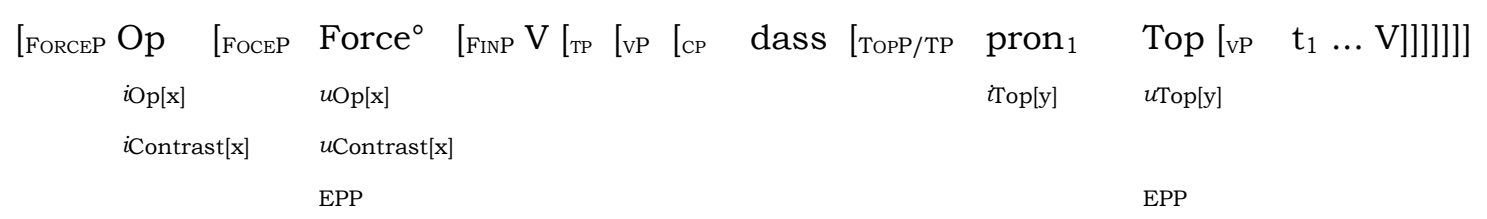

For amount quantifiers as in (19) we assume that their restriction is intrinsically incompatible with $i$ Top so that some other element has to occupy SpecTopP. As a consequence, the restriction can bear iContrast and move via the intermediate SpecCP, thereby satisfying $u$ Contrast on dass. The derivation thus proceeds as in (35).

With non-contrastables like leider, cf. (28), things are also straightforward in our system: Such elements do not have an iContrast feature and therefore fail to satisfy $u$ Contrast on the intermediate $\mathrm{C}$ if they move long-distance (which would be an instance of FF). Since these elements do not result from amalgamation with an operator, there is no other element that could check $u$ Contrast on the intermediate $\mathrm{C}$ so that the derivation crashes.

Our account thus crucially relies on topicality. For DPs, there is much evidence that scrambling - ignoring here focus scrambling - targets A-positions. Thus, A'-movement may in principle start from a scrambling position. According to our reasoning this can, however, not be the case once scrambling has targeted the position reserved for sentence topics. ${ }^{37}$

(ii) Who do you think that he will win in the final of Wimbledon 2009?? http: / /www.fanpop.com/spots / tennis / picks/results/262913/who-think-will-win-final-wimbledon$2009 \quad$ [05.05.2012]

(iii) Who do you think that he will save those who blasphemed him or those who love him? http://www.thebereans.net/forum2/archive/index.php/t-50913.html [05.05.2012]

36 We assume, as is standard, that such movement triggering features are in principle optional (for instance, they must be absent when there is no A'-dependency). If they are not present, long-distance movement will not be an option and a grammatical result with an A'-dependency is only possible if a language allows for resumption.

37 To see that scrambling inside VP does not hamper subsequent A'-movement, consider the following example in which one can assume that the DO has been scrambled to the left of IO as shown in (ii).

(i) Was glaubst du, dass der Chef wohl alles der Stiftung vermacht hat? what believe you that the boss PRT all the.DAT foundation donated has 'What all do you think that the boss has donated to the foundation?' 
(33)/(34) capture the anti-adjacency effect by making reference to topicality rather than to subjecthood. In German, there are various ways to fill the topic position. We have considered scrambled objects as well as overt or even covert stage topics in the sense of Erteschik-Shir. As a result of its typological properties, English is more restricted. English looks like displaying a subject effect, but one can argue that the "high" subject in English equals the topic, i.e. one can assume that T can bear uTop. Evidence that this leads to the correct generalization for English, too, has been provided by locative inversion as shown in (3), which we repeat here for convenience.

[In which villages] ${ }_{1}$ do you believe ( ${ }^{*}$ that) $t_{1}$ can be found examples of this cuisine?

To summarize at this point, we have argued that an explanation of the that-trace effect can be achieved without adding unmotivated elements to the theory. Even if there is no deeper account of why SpecCP rejects non-contrastable XPs, the data suggest this as a reliable fact. Sentence topics do not meet this requirement and as a result cannot be extracted via SpecCP. The obvious question is then how to deal with local extraction and extraction from nullcomplementizer complements. This is what we turn to in the following section.

\section{Local extraction + long-distance extraction without dass}

\subsection{Local extraction}

Recall from section 4 that there is a distinction between formal fronting and focus fronting. Weak pronouns such as es and man or uncontrastable adverbs such as leider could be shown to move to SpecFinP but not to SpecForceP/SpecCP. The question is then whether operators move uniformly in the style of focus fronting or not. With respect to English, there is a classical debate whether the wh-subject moves away from SpecTP or not. The surface facts strongly suggests that it does not. 38

(40) a. Who saw Mary?

b. *Who1 did t1 see Mary? (with non-emphatic do)

(41) a. *Who1 Mary saw t ?

b. Who ${ }_{1}$ did Mary see $t_{1}$ ?

Most strikingly, do-support is absent in local subject questions, cf. (40). In an OTaccount, Grimshaw (1997) proposed a constraint OP-SPEC which is satisfied as soon as an operator is in a position from where it can bind a variable. This need not be SpecCP. Rather, any position from where it has scope over the proposition is sufficient (see also Haider, 2004)._We will adopt a modified version of this idea: Again, we take surface elements like who to consist of operator + restriction. The restriction will move to SpecTP because of the EPP, and possibly because it is the default topic. Op is base-generated in ForceP where it checks $u O p$ and $u$ Contrast. Further movement of the restriction would require an additional projection and thus do-support.

(ii) Was ${ }_{1}$ glaubst du, [cP $t_{1}$ dass der Chef wohl $\left[{ }_{\nu P} \ldots \text { [ } t_{1} \text { alles }\right]_{2}$ der Stiftung $t_{2}$ vermacht hat $\left.]\right]$ ?

38 See the proposal that movement must not apply string-vacuously. Gazdar (1981), Chung \& McCloskey (1983), Chomsky (1986: ch.9), Grimshaw (1997) and Haider (2004) argue in one way or the other that the wh-subject does not move. 
It turns out to be unnecessary for convergence. Since operator and restriction are adjacent, they can be amalgamated. In object questions and in long-distance movement, this option is not available because for operator and restriction to be adjacent, both have to occur above the (matrix) TP. Therefore, the restriction moves to SpecForceP to check $u$ Contrast (while the operator checks $u \mathrm{Op}$ ). We assume that $d o$-support is necessary once ForceP is doubly filled, which implies that it is unavoidable with non-subject questions and in long-distance movement.

Turning now to German, we assume that the verb in V2-clauses is in Fin, and that there is an operator position above it, viz. ForceP, whose head bears $u \mathrm{Op}$ and $u$ Contrast in whsentences. As before, the operator-part is directly inserted in SpecForceP. The restriction originates in the theta-position and can either move to the topic position in the middle-field if it has the respective feature ( $i$ Top), or directly to SpecFinP as part of the verb-second constraint. Consider first a sentence like (40).

$$
\begin{aligned}
& \text { Wer hat gelacht? } \\
& \text { who has laughed } \\
& \text { 'Who laughed?' }
\end{aligned}
$$

In (40), the wh-DP is the only possible topic. We assume that the restrictor PERSON bears the feature $i$ Top and moves to Top (which has $u$ Top) and from there via FF to Fin. Since the restriction is incompatible with $i$ Contrast, $u$ Contrast of Force is checked by the operator ( $F F$ is arguably triggered by an EPP-feature of Fin).

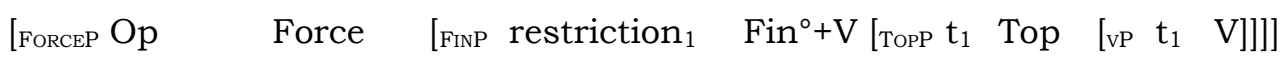

$$
\begin{aligned}
& \begin{array}{ll}
i \mathrm{Op}[\mathrm{x}] & u \mathrm{Op}[\mathrm{x}] \\
i \text { Contrast }[\mathrm{x}] & u \text { Contrast[x] }
\end{array} \\
& \text { EPP }
\end{aligned}
$$

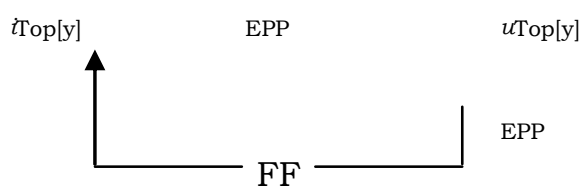

Operator and restriction are linearly adjacent; thus, amalgamation is successful. Since the two elements undergo independent checking operations and no intermediate $\mathrm{C}$ with $u$ Contrast is involved, no violation of our variety of the Improper Movement constraint obtains. Semantically, the wh-operator (which is intrinsically contrastive as it considers alternatives) ranges over members of the set which is presupposed, and which is denoted by the sentence topic. Recall here that the topic is non-contrastive in the sense of Contrast $_{A}$ but nevertheless amenable to contrastivity as far as alternatives of the value of the topic are concerned. 39

If the sentence topic is a non-subject, the wh-subject will move to Force in the style of focus fronting. Consider (40), where intuitively das Buch (the book) is topic.

Wer hat das Buch geklaut?

who has the book stolen

'Who stole the book?'

The definite DP - XP in (45) - bears $i$ Top and is thus moved to the formally available Topposition. In this case, the restrictor of the wh-phrase, here again PERSON, can be marked with

39 Our analysis seems to imply that wh-subjects that originate as aboutness topics are obligatorily contrastive (Contrast $\mathrm{T}$ in our sense) since the operator chooses from a contextually determined set. One might therefore expect only D-linked wh-phrases to occur, but no simplex wh-items. For reasons of space, we have to leave a full discussion of this issue for another occasion. 
the feature iContrast. In that case, it undergoes focus fronting to check uContrast on Force (while $u \mathrm{Op}$ is checked by the operator). The derivation is as in (45).

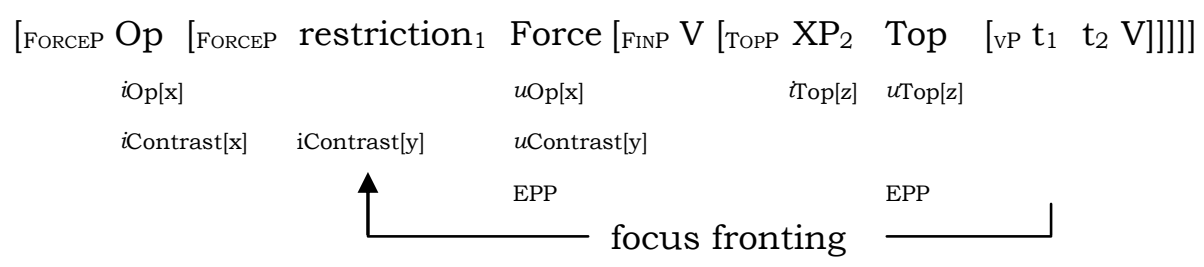

Again, operator and restriction are adjacent so that amalgamation is possible. The restriction is ContrastA due to its origin in the assertive part of the sentence.

To sum up, local extraction can involve contrastivity but it need not involve it. The assumption is that Force can check contrastivity (as induced by the assertive part of the sentence) similarly to C. Force can, however, also check contrastivity as it emerges from the semantic range which the existentially presupposed topic establishes. This is what we may call Contrast (cf. note 28). Importantly, local extraction is compatible with focus fronting but does not involve the Constraint on A'-extraction that was formulated in (34). This constraint is crucial for extraction across $\mathrm{C}$ because for successful amalgamation of operator and restrictor, the restrictor has to pass through SpecCP. As we have argued at length, topical elements (which lack the assertioninduced feature iContrast) are unable to value the feature $u$ Contrast on C. ${ }^{40}$

\subsection{Long-distance extraction without complementizer: parentheticals}

What has been said in section 5.1 should suffice to set the stage for an account of long extraction without involvement of an overt complementizer as in (2), which we reproduce in (46).

Who ${ }_{1}$ do you believe $t_{1}$ likes Mary?

No subject- or topic-effect arises in this type of examples. Similarly, extraction from V2clauses is always grammatical in German.

40 One must be careful about one prediction that our analysis seems to make. We predict that an XP that has undergone A'-movement to Spec, CP cannot be the topic in the root clause. The following two examples seem to contradict our analysis.

(i) Speaking of Tom, Dick and Harry, ... who (of them) 1 do you believe that under the given circumstances $t_{1}$ could have been the victim?

[Subject extraction from a lower position]

(ii) Speaking of Tom, Dick and Harry, ... who (of them) do you believe that we should give the Nobel prize?

[Object extraction]

Two considerations militate against such a conclusion: First of all, the aboutness test which is used in (i) and (ii) (speaking of ..., as for $X$... etc.) is not sensitive to the sentence topic but may rather pick up any discourse referent. Secondly, it would be a mistake to believe that topicality - essentially a discourse property - can be passed from one clause to the next like, say, grammatical function or Case. It is more likely that information structure is computed for each clause. The issue is too complex to address it in a footnote. For the moment it is only important to see that cases like (i) and (ii) are no challenge to the theory presented; cf. also fn. (54) 
Wer glaubst du raucht?

who believe you smokes

'Who do you think smokes/is a smoker?'

For German, Reis (1995) has argued that cases like (47) do not necessarily involve cyclic movement. There is a competing analysis by which the bridge construction is a PARENTHETICAL. Some linguists reject the idea that a V1-construction like glaubst $d u$ or do you think can be a parenthetical. However, there is strong evidence that this must be a possibility. Consider the case in (48) where glaubst $d u$ appears in a position lower than the one which is expected under the long extraction analysis.

Wer hat, glaubst du, dem Opa nochmal einen Schnaps eingeschenkt? who has believe you the.DAT grandpa again a schnaps poured 'Who do you think poured grandpa another schnaps?'

It can also follow the entire question in the style of what Ross (1973) calls SLIFTING.

Wer hat dem Opa nochmal einen Schnaps eingeschenkt, glaubst du?
who has the.DAT grandpa again a schnaps poured believe you
'Who poured grandpa another schnaps, do you think?'

(48) is by all criteria a root clause. The parenthetical could at best be analyzed as involving an empty operator that is somehow coindexed with the root question. ${ }^{41}$ There is another piece of evidence that must be considered in the present context: extraction from V2-clauses is not constrained by potential contrastability. Compare the following examples with the ungrammatical ones in (27) and (28). ${ }^{42}$

41 Cf. Steinbach (2007) and the discussion of further proposals in Viesel (2011). To be sure, the parenthesis analysis is by no means innocent. It creates questions about the V2-constraint because in this analysis the material immediately preceding the finite verb can actually not be its specifier. Furthermore, this material does not necessarily consist of a single constituent while this is is normally a solid column on which the grammar of V2 rests.

42 According to Cardinaletti (2004), (50)a/b should be ungrammatical. In her account this is so because they involve "weak subjects". Weak subjects are universally restricted to a low nominative- and phifeature-checking position. We admit that (50)a/b are degraded once the V1-construction is prosodically separated but since V1-parentheses are prosodically integrated, the problem does not arise. Notice also that there must be a phonological factor involved. Examples of this sort improve when the weak subject is immediately followed by the verb as in

(i) Es hat, glaube ich, geregnet.

(ii) Man sollte, finde ich, nicht so viel Lärm machen.

Nevertheless, it is easy to find examples like (50) on the internet with nothing but the non-contrastable element before the parenthetical.

(iii) Man finde ich sollte für das Buch der Richter den Titel "Wegbegradiger" oder was one find I should for the book (of) the judges the title "path-straightener" or something

\section{ähnliches wählen}

similar choose 
(50) a. Es, glaube ich, hat geregnet.

it believe I has rained

'It has rained, I believe.'

b. Man, finde ich, sollte nicht so viel Lärm machen.

one find I should not so much noise make

'One should not make so much noise, I think.'

c. Leider, sagte Karl, hat keiner dem alten Mann geholfen.

unfortunately said Carl has no.one the.DAT old man helped

'Unfortunately, no one helped the old man, said Carl.'

In these cases, long extraction of the non-contrastables es, man and leider would be utterly unexpected. Given the option of parenthetical insertion, the fronting that is seen here is the result of FF and not of focus fronting. This implies that examples like (47) are to be analyzed as in (43).

Kiziak $(2007,2010)$ offers convincing evidence in favor of the parenthesis analysis from judgments which were elicited using the magnitude estimation method. The central result of her study is that in German extraction from dass-clauses is fairly tolerant with respect to matrix predicates that serve as bridge verbs whereas extraction from V2-clauses is comparatively intolerant and declines rapidly when matrix predicates are used which play no role in bona fide parenthesis. Viesel (2011) offers a detailed study which shows that the parenthesis option depends not only on the choice of the predicate but also on the choice of person, $1^{\text {st }}$ and $2^{\text {nd }}$ person being privileged over $3^{\text {rd }}$ person. ${ }^{43}$

'I think one should choose for the Book of Judges the title "straightener of the path" or something similar.'

http://wiki.volxbibel.com/Benutzer_Diskussion:Martin [04.05.2012]

(iv) die Sachen zusammen gesucht, die man finde ich braucht

the things together searched which one find I needs

'collected the things which, I think, one needs'

http://www.das-hamsterforum.de/index.php?page=Thread\&threadID=96704 [04.05.2012]

(v) es finde ich hat auch etwas mit dem essen zu tun ob es schlimmer wird

it find I has also something with the eating to do if it worse gets

'I think it also has to do with eating whether it gets worse ...'

http://www.rund-ums-baby.de/forenarchiv/schwanger-wer-noch/Neurodermitis_50219.htm

[04.06.2012]

43 In spoken language, glaubst $d u$ and glaub ich tend to show enhanced cliticization and ultimately signs of grammaticalization as in $2^{\text {nd }}$ person glaubsch and $1^{\text {st }}$ person glaub. 
Unlike for German, the parenthesis analysis has hardly ever been considered for English, but in what follows, we will argue that such an analysis is not only feasible but in fact necessary. This implies that sentences like (46) should be treated exactly like (40).

It is actually somewhat surprising that the parenthesis analysis has not played much of a role in the literature on English because the situation is not too different. First of all, bridge elements like do you think/believe can float away. The following examples were found on the internet.

(51) a. "Suppose you do finally retire as leader, who will, do you think, be your successor?" Mr. Croker was asked. ...

http:/ / www.google.de/search?hl=de\&as_qdr=all\&q=+\%22who+will+do+you+think\%22\&bt $\mathrm{nG}=$ Suche\&meta $=\quad[04.06 .2012]$

b. Who is, do you think, the best female Tejano vocalist at the moment? http://library.uta.edu/tejanovoices/xml/CMAS_009.xml [04.05.2012]

c. What is do you believe the main reason for the improvement of DWs blades? http://www.rotaryforum.com/forum/showthread.php?t=20972\&page=3 [04.05.2012]

Examples with the bridge construction in clause final position ("slifting") are very frequent.

(52) a. Who will win do you think?

http:/ /www.farmlanebooks.co.uk/2012/who-will-be-shortlisted-for-the-2012-orangeprize/ [04.06.2012]

b. What will happen, do you think, if I put it [the cabbage, BP \& MS] out in the garage, where it's...

http://www.chow.com/food-news/55232/how-to-make-sauerkraut/ [04.06.2012]

c. When was this painting made, do you think?

http://www.slideshare.net/ladymandona/famous-paintings [04.06.2012]

Secondly, there are cases for which the extraction theory would predict that the matrix verb selects the wrong semantic type of $\mathrm{CP}$. The verb wonder requires an interrogative complement. This is verified by the semantic ill-formedness of (53)a. The surprise is why (53)b, a datum from the internet, is grammatical. ${ }^{44}$

(53) a. *Who1 did John wonder that next week t1 will meet Susan?

b. Who do you wonder has caused this theft?

http://www.birthdaypartyideas.com/html/scooby_parties_15.html [05 02.2010]

A parenthesis analysis as suggested for German can explain this contrast: In (53)a there is no way to avoid the s-selection conflict; in (53)b, however, there is a simplex wh-question - Who has caused the theft? - which happens to be a root clause, and which happens to be interrupted by the parenthetical do you wonder. ${ }^{45}$ Unlike German, English shows an asymmetry in the option

44 In (53)a, next week has been added to avoid the that-t effect and thus to guarantee that the example is excluded for only one reason, namely the deviant semantic selection of wonder. The issue is debated even outside linguistics as shown by an internet chat which can be found under: http:/ /iteralminded.wordpress.com/2009/01/27/who-may-i-ask-is-calling/

45 Jane Grimshaw (p.c.) suggests that inversion (I-to-C movement) in the SAI-fragment is only possible where the scope of an "affective" operator is marked. Accordingly, What, do you wonder, is this all about? 
of permitting a parenthetical analysis: Only subject questions allow it. Consider the contrast in (54), where the parenthesis is shown as missing. The result is that (54)b leaves a valid root whquestion whereas (54)a does not. ${ }^{46}$

(54) a. *Who did John believe Susan will meet?
b. Who did John believe will meet Susan?

involves two instances of inversion; what must have taken scope above as well as below wonder. The parenthesis solution offers a way out of this dilemma. There is only a simple wh-question (What is this all about?) into which the SAI-fragment is inserted. If the parenthesis solution turns out to be untenable, such examples as well as examples of subject questions like (53)b would have to be relegated to the realm of speech errors (whatever this would mean). More about this in the next footnote.

46 Examples which show apparent "double inversion" (see footnote 45) may not be standard but occur rather frequently. Here are some randomly collected examples:

(i) Who do you think did he visit?

http://twitter.com/\#!/fashionkingkr [03.06.2012]

(ii) Ideally - what do you believe did he need then? He asks softly.

http://m.fanfiction.net/s/7756442/3/ [03.06.2012]

(iii) How do you think did he make it?

http://www.youtube.com/user/georgmeir [04.06.2012]

(iv) How do you think did he simply disappear from history after 1945 ?

http://in.answers.yahoo.com/question/index?qid=20110812214411AAhkWpw [04.06.2012]

To us it would be surprising that these are all speech errors. The parenthesis hypothesis offers a serious alternative explanation: There is a matrix clause which - due to non-subject wh-movement - shows dosupport. V1-Subject-verb chunks are grammaticalized as integrated parentheticals; these parentheticals may enter simplex questions with inversion. Thus, it seems highly unlikely that we are facing some kind of unmotivated "double inversion" here. Interesting support for our conjecture comes from the following quote from an internet discussion about English grammar by non-linguists in which one discussant reveals his/her intuitions in a hesitating but nonetheless highly revealing way: "In vernacular, I suppose you could speak with the invisible commas to make the sentence grammatically correct (this is where I became so perplexed). I.e., "What, do you think, is the best way to learn English?" I believe this would be my personally most natural way of asking this question. I tend to speak just a little differently than most people, however, so I'm curious about what others think."

http://www.englishforums.com/English/Interrogatives/qxhlv/post.htm [03.06.2012]

Although this is an unwarranted intuition by an untrained native speaker, we take it as constituting strong support for an analysis in terms of parenthetical insertion. 
Nevertheless, the undeleted version of (54)a - Who did John believe Susan will meet? - is grammatical. From this it follows that long-distance extraction must have taken place, and that this case involves in all likelihood a zero complementizer.

The parenthesis explanation makes strong predictions whose empirical validity we cannot hope to control in the necessary detail in this study. One such prediction is that verbs of denial could appear in the matrix VP of type (54)a but not in the matrix VP of type (54)b. The explanation is straightforward: If the wh-clause is a root clause, the speaker presents a presupposition, e.g. in (54)b that someone will meet Susan. This presupposition is in conflict with the parenthetical if the parenthetical involves a verb of denial because the parenthesis then denies the presupposition. Consider now (55)a. The predicate deny is applicable because it does not take scope over the question. ${ }^{47}$ For $(55) \mathrm{b}$ we choose a root question with a slifted parenthesis of denial. Here the conflict arises.

a. Who did you deny (that) Susan will meet?

b. *Who will Susan meet, did you deny?

In (55)b, the verb has scope over the question. It is in conflict with the presupposition that Susan will meet someone. The crucial question is whether verbs of denial allow cases of subject extraction, i.e. examples in which the parenthesis analysis is excluded for the same reason as in (55)b. In such a case, the only semantically viable analysis would enforce extraction from a CP with a zero complementizer. The structure would be the same as in subject extraction from a that-CP. Therefore the result should be ungrammatical. Consider the example in (56).

\section{Who did you deny/doubt will win the prize?}

We are not sure about the status of these examples. They sound better than that-trace violations. In order to explore their status, we used a number of high frequency constructions with the templates who \{did / do / can / could / should \} y you / he / she \} [VERB] for internet searches with the values for [VERB] being agree, assume, confirm, doubt, deny, mention, and regret. The set is, of course, only enough for a spot check to see whether they can be used as bridge verbs. Examples were found only for the verbs agree, assume and regret. Examples with the verbs agree and regret had to be excluded as they occurred only in constructed examples from linguistics papers. The examples with the matrix verb assume are compatible with a parenthesis analysis. ${ }^{48} \mathrm{~A}$ single cursory study of this kind cannot be conclusive, of course. Nevertheless, the

47 The only example from the internet we found is the following

(i) What do you deny that it had, at the singing and shouting and ...?

http://www.google.de/interstitial?url=http://hostflux.com/Wisconsin_Web_Hosting/KOHLER_Web_Hosti ng/1613/botox-cluster-headaches.html

48 Here are some examples:

(i) When you write only in English who do you assume will be your reader?

(ii) So with that, who would you assume is now playing in the 2007 Stanley Cup? 
fact that no examples of type (56) could be found should nourish the belief that they are in fact excluded from the competence grammar of English speakers. Their non-occurrence indirectly supports the availability of the parenthesis analysis in examples of type (54)b.

Our preliminary conclusion is that in cases of purported grammatical subject extraction from zero complementizer complements we may in reality deal with a matrix question into which a V1-parenthetical has been inserted. Extraction in this case amounts to FF and not to focus fronting. We have to leave it to a more detailed study to explore the various aspects of our proposal. For the time being it should suffice to see that we have offered a plausible alternative to leading analyses which must postulate special agreement relations between an empty C-head and the subject trace as in Rizzi (1990) or an alternative checker under assumptions of a "subject criterion" which leaves the wh-subject in a "non-criterial" position as in Rizzi \& Shlonsky (2007). Our theory relies on the distinction between FF-style/non-contrastive movement and focus/contrastive movement and the role of $u$ Contrast on intermediate $\mathrm{C}$-heads. According to our analysis, a sentence/aboutness topic is unable to value this feature.

In the following final section, before we reach the conclusion, we will take a look at a case of resumption in Zurich German (Alemannic) which at first sight seems to be surprising but finds a natural explanation within the theory developed that far.

\section{Resumption resulting from Improper Movement}

This second part of the article extends the analysis of that-trace effects to a different area, viz. resumption in relativization. We will argue that the presence of $u$ Contrast on $\mathrm{C}$ also has drastic consequences for relativization in German and its varieties. We take the restriction of relative operators to bear a topic feature so that is has to target the high topic position in the middle field. As a consequence, it cannot move via SpecCP into the matrix clause. Since amalgamation fails, the movement derivation crashes. In contrast to Standard German, varieties of Alemannic provide a repair strategy in that they can employ resumption, a base-generation strategy that avoids the problem of the movement derivation.

\subsection{Resumption in Zurich German relative clauses}

The data on Swiss German relativization that are used in this paper are taken from Zurich German (ZG), but Zurich German relatives can be taken to be representative of relativization in Alemannic in general (modulo certain minor dialectal differences, cf. Salzmann 2008, 2009b, to appear, Salzmann \& Seiler 2010). Zurich German relative clauses are introduced by an invariant complementizer wo (won before unstressed vowels). There are no relative pronouns as in Standard German (except in the relativization of adverbial relations). In certain

We wish to thank Benedikt Grimmler, who ran these searches in August 2007, and to Peter Culicover for stirring this discussion. Our Canadian informants David Bird and Amanda Pounder accept slifting in examples with assume as well as with suppose, imagine, guess, predict, all of which seem to be able to be used as integrated parentheticals:

(iii) When will the guests arrive, do you $\{$ suppose / imagine $\}$ ?

(iv) When will the guests arrive, would you $\{$ guess / predict $\}$ ? 
grammatical relations, a resumptive pronoun appears instead of a gap. In the default case those resumptives behave like weak personal pronouns and are fronted to the Wackernagel position or are cliticized onto $\mathrm{C}$ (or, in the case of oblique objects, onto the governing preposition). According to earlier descriptions, the distribution of resumptive pronouns in restrictive local relativization follows Keenan \& Comrie's (1977) Accessibility Hierarchy: Resumptive pronouns are found from the dative object on downwards, but crucially not for subjects and direct objects. This is illustrated by the following examples (cf. Weber 1964, Van Riemsdijk 1989): ${ }^{49}$
a. $d$ Frau, wo ("si) immer $z$ spaat chunt the woman $\mathrm{C}$ (she) always too late comes
'the woman who is always late'
b. es Bild, wo (*s) niemert cha zale a picture $\mathrm{C}$ (it) nobody can pay 'a picture that nobody can afford'
c. de Bueb, wo mer *(em) es Velo versproche händ the boy $\mathrm{C}$ we (he.DAT) a bike promised have.1PL 'the boy we promised a bike'

(subject: wo + gap) (indirect object: $w o+$ res.)

d. $d$ Frau, won $i$ von *(ere) es Buech überchoo han the woman $\mathrm{C}$ I from (she) a book got have.1SG 'the woman from whom I got a book' (P-object: wo + res.)

While nominative and accusative are recoverable in gap-relatives, datives and PPs require overt resumptives.

Additionally, resumptive pronouns occur inside islands, in positions from where regular wh-extraction is impossible; islands are henceforth enclosed in angled brackets, cf. Salzmann (2006b: 331): 50

(58) a. deAutor, wo d Marie < jedes Buech, won *(er) schriibt >, sofort chaufft the author C the Mary every book C he writes immediately buys 'the author such that Mary immediately buys every book he writes' (CNPC)

b. de Sänger, woni mi fröi, <wänn mer *(en) im Fernseh bringt> the singer C I me be.happy when one him on TV brings 'the singer such that I am happy when they show him on TV' (adjunct island)

a. *[Wele Autor $]_{1}$ chauft d Marie < jedes Buech, wo t $t_{1} /$ er schriibt $>$ ? Which author buys the Mary every book $\mathrm{C}$ he writes lit.: 'Which author does Mary buy every book that writes?' $\quad$ (CNPC)

49 For the transcription see Salzmann (2006: 320, fn. 259). For possessor relativization, cf. Salzmann (2011). Free relatives require $w$-relative pronouns that leave gaps, cf. van Riemsdijk (1989). The syntax of dative relativization is more complex. With certain verbs (especially experiencer verbs), neither a gap nor a resumptive leads to a completely well-formed result, cf. Salzmann (2006b: 323-326). Additionally, there generally is a lot of inter- and intra-speaker variation: many speakers accept both gap and resumptive, cf. Salzmann (2008/2009b, to appear), Salzmann \& Seiler (2010).

50 Wh-extraction does not improve with resumption. We will come back to the incompatibility of regular whmovement with resumption in 6.7 below, cf. also Salzmann (2011). 

b. *[Wele Sänger $]_{1}$ fröisch
di, <wänn mer
$t_{1} /$ en im
Fernseh
bringt $>$ ?
which singer be.happy.2s you when one him on TV
brings
lit.: 'Which singer are you happy when they show on TV?'
(adjunct island)

Gaps and resumptives are thus in complementary distribution.

\subsection{Explaining the distribution of resumptive pronouns}

The distribution of resumptives is governed by two factors: Resumptives amnesty locality violations, cf. (58). This also covers cases like (57)d since PPs are strong islands in German and its varieties. Dative resumptives, however, require a different explanation because extraction of dative objects is possible. Dative resumptives are the reflex of a realizational constraint operative in most German varieties that requires the overt realization of oblique case, cf. Bayer et al. (2001), Salzmann (2006b, 2008, 2009b) for details. Resumptives, thus, act as a last resort, occurring only when gap-derivations fail. Since subjects and direct objects are realized by non-oblique cases, they do not have to be expressed overtly; resumptives are therefore not necessary. This statement is less innocuous than it sounds and will be qualified in the next section.

\subsection{Resumption involves base-generation}

While gap relatives can be straightforwardly analyzed as involving movement, the syntax of resumption has been subject to some controversy lately. ${ }^{51}$ While base-generation was the default until 1990, several linguists have proposed movement accounts since then, e.g. Pesetsky (1998), Aoun et al. (2001), Boeckx (2003), Bianchi (2004). While a movement account, or one based on Agree, may be adequate for languages where resumption is sensitive to locality (cf. e.g. Boeckx 2003, Alexopoulou 2006), any movement account is confronted with serious difficulties once resumption is not sensitive to locality, as in ZG, cf. (58). Movement accounts of resumption have to resort to rather unorthodox mechanisms, or constraints, to make movement out of islands possible (e.g. resumption as LF-movement as in Demirdache 1991, locality as a PFconstraint, cf. Pesetsky 1998, or movement without Agree as in Boeckx 2003). These mechanisms complicate the grammar of locality in unmotivated ways, or fail altogether, cf. Salzmann (2008: 105-108, 2009a: 33-39, 2011, to appear) for detailed argumentation. Under base-generation, the distribution of (non-dative) resumptives follows straightforwardly since islands and PPs bar extraction and consequently can only be bridged by means of binding as in base-generation. One frequent argument in favor of a movement analysis of resumption are reconstruction effects under resumption (e.g. Aoun et al. 2001). Such effects can indeed be found in ZG, even reconstruction into islands (Salzmann 2008, 2009a, 2011, to appear). However, we do not think that reconstruction should always be taken as a waterproof diagnostic for movement because the relationship between movement and reconstruction has generally turned out to be imperfect: There are instances of reconstruction without prior movement, and there are instances of movement without reconstruction, cf. the discussion in Salzmann 2008, 2009a, 2011, to appear. Under base-generation, the locality effects fall out nicely; to account for reconstruction under resumption (and thus base-generation), alternative mechanisms are available such as the NPellipsis theory of resumption, cf. Guilliot \& Malkawi (2006). We therefore opt for a base-generation

51 See van Riemsdijk (1989) for an analysis where gap relatives are based on resumptive relatives. Salzmann (2009a: 41-42, 2009b: 143-145, 2009c: 66-67) argues extensively against this position, showing that gap relatives differ from resumptive relatives in a number of important properties so that a unification is undesirable. 
analysis of resumption in ZG. Note that this means that gap and resumptive relatives involve very different derivations.

We are now in a position to be somewhat more precise about the syntax of subject and direct object relativization. In the previous subsection, we remarked rather casually that resumptives are not necessary because they are realized by non-oblique cases. However, since the grammar provides a mechanism that can produce resumptive structures, and since no obvious syntactic constraint prevents resumptives for subjects and direct objects, we must assume that resumptive derivations converge for these relations as well. Given that only gap derivations are grammatical in these environments, we can conclude that they block resumptive derivations. For present purposes it is sufficient to know that movement is preferred in case both movement and base-generation converge, see Salzmann (2009a/c, to appear) where this preference is linked to a translocal constraint in $Z G$ that prefers internal merge over external merge.

Before we turn to a precise implementation of movement and base-generation derivations, we need to look at one puzzle in the distribution of resumptives that will motivate the feature specifications on relative operators and relative complementizers.

\subsection{The puzzle: long-distance relativization}

So far, the distribution of resumptive pronouns in $Z G$ is straightforward: they only occur as a last resort when movement derivations fail. Before this background it is rather surprising that resumptives become obligatory once relativization crosses a sentence boundary: in longdistance relativization, resumptives become obligatory for all grammatical relations, including subjects and direct objects (van Riemsdijk 1989, 2008, Salzmann 2006b):

a. d Frau, woni gsäit han, dass *(si) immer $z$ spaat chunt the woman $\mathrm{C} I$ said have.1s that she always too late comes 'the woman who I said is always late'

emb. SU

b. es Bild, woni vermuete, dass *(es) niemert cha zale a picture $\mathrm{C}$ I suspect that it no.one can pay 'a picture that I suspect nobody can afford' emb. DO

Given the factors governing the distribution of resumptives that we have identified above this is surprising. Oblique Case is not at stake, and locality seems to be an unlikely candidate given that corresponding long wh-extractions (of non-topics) are fully grammatical (resumption is not an option in regular wh-movement, cf. 6.7 below):

a. [Wele Maa] $]_{1}$ häsch gsäit, dass geschter $t_{1}$ choo isch? which man have.2s said that yesterday come is 'Which man did you say came yesterday?'

b. [Wele Maa] $]_{1}$ häsch gsäit, dass $s$ Rägeli $t_{1}$ küsst hät? which man have.2s said that the Regula kissed has 'Which man did you say that Regula kissed?' 
But if locality is not at stake, what else prevents a movement derivation in long-distance relativization?52

\subsection{Relative operators cannot check uContrast - resumption as repair}

We would like to propose that long-distance movement in relativization fails for the same reason that long-distance movement of (sentence) topics fails in wh-movement: The topical restriction of a relative operator has to move via SpecCP into the matrix clause to amalgamate with the operator. In wh-movement, this does not always happen because German provides ways of extracting from a position below TopP. In relativization, we submit, this is not possible because the restriction of (specific, cf. below) relative operators is inherently topical and therefore always targets SpecTopP on its way to the final landing site (on the topicality of the relative pronoun, cf. Bresnan \& Mchombo 1987, Bianchi 2004, and Lambrecht 1994: 129-130 who argues that the referent of the head NP enters an aboutness relation with a proposition via the relative pronoun). ${ }^{53}$ Due to its semantics, the restriction of relative operators is incompatible with iContrast. As a consequence, if on its path it passes a $\mathrm{C}$ with $u$ Contrast, it will be unable to value that feature so that the derivation eventually crashes. A base-generation derivation, however, converges because the intermediate $\mathrm{C}$ does not contain any attracting features and consequently no $u$ Contrast. The short-distance/long-distance asymmetry (57)a/b vs. (60) is again due to the fact that the topic restriction does not pass through a head with $u$ Contrast in short extraction. Given the semantics of relative clauses where alternatives do not play a role, we assume that no $u$ Contrast is involved in the checking operations involving the highest head of the matrix clause and the operator. As a consequence, what is crucial is $u$ Contrast on the intermediate complementizer dass. ${ }^{54}$

52 A different (re-)analysis of long distance relativization is proposed in Salzmann (2006b), building on van Riemsdijk (2008), where it is argued that what looks like a long-distance dependency actually involves short extraction in the matrix clause and a somewhat different type of pronoun binding, i.e. a more abstract version of ex. (70) below; for reasons of space, we cannot provide a comparison of the two approaches; cf. also fn. 59.

53 Since relative operators always move on to a position above SpecTopP, the intermediate movement step can only be shown indirectly by means of floating quantifiers that can be stranded above discourse topics:

(i) die Leute, die alle den Peter vermutlich nicht mögen

the people who all the Peter probably not like (Standard German)

Admittedly, the quantifier can also be stranded in lower positions. We will assume that it is essentially optional where a quantifier is stranded and that relative operators always move via SpecTopP even in cases where this cannot be inferred from the position of floating quantifiers.

54 Our analysis seems to predict that once a constituent has undergone A'-movement (to an intermediate position), it cannot become a (sentence) topic in the matrix clause (recall also the discussion in fn. 40). Long relativization would in principle seem to instantiate such a constellation (as does long-distance scrambling). In German and its varieties it is ruled out because of $u$ Contrast on the intermediate $\mathrm{C}$ (amount relatives constitute an exception, cf. 6.6.1 below, but they arguably do not involve topicality in the main clause). While Swiss German can resort to resumption in this case, long relativization in Standard German is strongly degraded if not ungrammatical, cf. section 6.6.2 below. Long relativization in English, however, is unproblematic, (as long as what is extracted does not correspond to the aboutness subject). This may be the case because topicality is not checked in the matrix clause syntactically or that information structureal properties are not inherited from one clause to the next. We have to leave this intricate issue for future research. 
As with wh-movement, we assume that the intermediate $\mathrm{C}$ in long-distance relativization is endowed with an EPP-feature that triggers successive-cyclic A'-movement and a subfeature $u$ Contrast. Regular relative operators are inherently specified as iOp while the restriction inherently bears $i$ Top and is thus incompatible with iContrast. Schematically, a potential longdistance derivation looks as follows (we omit the matrix TopP below wo for reasons of space). 55

$$
\begin{aligned}
& \text { * [Forcep Op Force [FinP restriction } \left.\left.\left.\left.\left.\left.1 \text { wo [vp [cr } t_{1} \mathrm{C} \text { [Topp } t_{1} \text { Top [vp [vp } t_{1} \mathrm{~V}\right] \mathrm{v}\right]\right]\right]\right]\right] \\
& \text { iOp[x] } u \text { Op[x] } \quad \text { iTop[y] } \quad u \text { Contrast[ ] } \quad u \text { Top[y] } \\
& \begin{array}{llll}
\text { EPP } & \text { EPP } & \text { EPP } & \text { EPP }
\end{array}
\end{aligned}
$$

As in wh-movement, the operator is directly inserted into ForceP to check $u O p$ of Force. The restrictive NP originates in the theta-position and then moves to TopP. For the restriction to amalgamate with Op, it has to move into the matrix clause via Spec, CP. And this is again where the violation occurs: This movement step violates (34): $u$ Contrast of the intermediate $C$ will remain unvalued and the derivation crashes.

The reason why local relativization is grammatical is simply the absence of an intermediate $\mathrm{C}$ and therefore the absence of the feature $u$ Contrast that could cause problems for the movement of the restriction. The derivation for local relativization looks as follows:

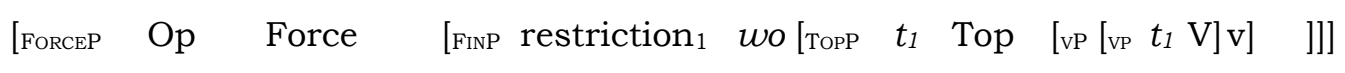

$$
\begin{aligned}
& \text { iOp[x] } \quad \text { OOp[x] } \quad \text { iTop[y] } \quad u \text { Top }[y] \\
& \begin{array}{lll}
\text { EPP } & \text { EPP } & \text { EPP }
\end{array}
\end{aligned}
$$

While the operator is directly inserted into ForceP, the restriction moves via TopP to FinP to amalgamate with Op. ${ }^{56}$

The base-generation derivation is similar to the movement derivation in major respects, the major difference being that the restriction can be realized by means of a phonologically independent element, viz. a resumptive pronoun, basically as already illustrated for wh-movement in (38). As a consequence, the restriction does not have to undergo movement to the matrix clause to amalgamate with Op. Thus, there is no movement via the embedded SpecCP whatsoever. Since

55 Following Rizzi (1997) we assume that Relative operators eventually move to ForceP, the same position into which we took wh-operators to move. This may not be completely obvious since restrictive relatives (unlike appositives) do not have independent illocutionary force. Given that there is little positional evidence in German for an articulated left periphery, we will, however, not posit more positions; rather, we will just posit two, one that is related to clause-typing ("ForceP") and one that is neutral ("FinP"); consequently, the label "Force" should not be taken too literally. Given that wo is a relative complementizer, it may be more desirable to have the $u \mathrm{Op}$ feature on wo rather than on F. One possibility to achieve this is to assume that a single head can combine the features corresponding to those of FinP and ForceP, so that several constituents can be attracted to its specifiers. Alternatively, one can take wo to lexicalize Force ${ }^{\circ}$. This seems to create problems for amalgamation, which however, may not be relevant in relativization, cf. fn. 56

56 Operator and restriction remain unpronounced/are PF-deleted in Zurich German and many other languages; in fact, the restriction is usually deleted even in languages with overt relative operators, at least under a traditional head-external analysis (or a Matching Analysis, cf. Salzmann 2006, where it is deleted under identity with material contained in the exernal head). This shows that there must be an independent trigger for movement of the restriction (viz. an EPP-feature). If, however, a head-raising analysis is adopted, the restriction would move on to become the head of the relative clause; this is not directly compatible with our assumptions about amalgamation. 
the intermediate $\mathrm{C}$ does not bear any attracting features and thus no $u$ Contrast, the problematic configuration in (34) does not arise. A base-generation derivation then looks as follows (as in (38), the resumptive moves to SpecTopP to check the topic feature): 57

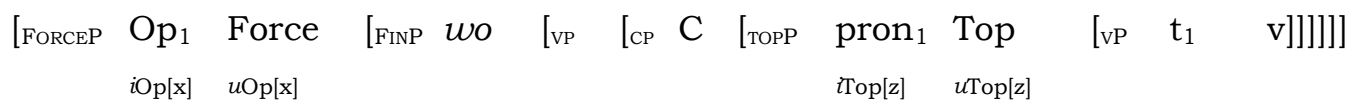

$$
\begin{aligned}
& \text { EPP }
\end{aligned}
$$

\subsection{Additional evidence}

In this subsection we will show that our proposal has coverage beyond the classical core examples and the comparative data considered so far.

\subsubsection{Amount relatives and comparatives: abstraction over a degree}

One of the crucial ingredients of our analysis is that the restriction of relative operators is incompatible with the feature $u$ Contrast due to its inherent topicality. However, this does not hold for all operators. Amount relatives involve abstraction over a degree, and the restriction consequently cannot target SpecTopP - just like in amount wh-questions (19), it is inherently incompatible with $i$ Top. As a consequence, the restriction should be able to move via SpecCP into the matrix clause to amalgamate with Op. We therefore expect long-distance relativization with amounts to be possible. This prediction is borne out: There are no resumptives with amount relatives:

$$
\begin{aligned}
& \text { di } 100 \text { Kilo, won er gsäit hät, dass er (*si/*das) uf d Waag bringt } \\
& \text { the } 100 \text { kilos } \mathrm{C} \text { he said has that he them/that on the scale brings } \\
& \text { the } 100 \text { kilos he said he weighs' }
\end{aligned}
$$

This means that there is long-distance relativization in $Z G$, but only in one very restricted area, namely where a relative operator (i.e. its restriction) is incompatible with topicality. The derivation for (65) can be sketched as follows:

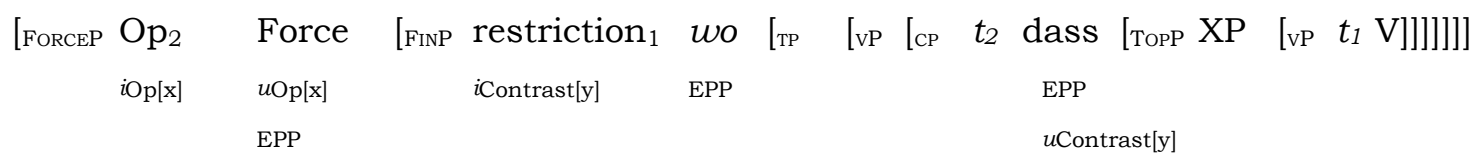

The restriction originates in the embedded clause, moves to Spec, CP to check $u$ Contrast of dass. Subsequently, it undergoes FF to SpecFinP (recall from the beginning of section 4.2 that the feature iContrast does not require the constituent to be actually used contrastively, it merely makes it eligible for contrastive use). Finally, the operator is merged in ForceP, checking $u \mathrm{Op}$ of Force. All features are checked, and the derivation converges.

A similar observation can be made for comparatives whose syntax is similar to that of relatives in that they also involve a silent operator and require resumptives in oblique positions (Salzmann 2006b: 375):

57 We assume here that $u \mathrm{Op}$ on $\mathrm{F}$ can be checked by means of external Merge. Alternatively, one would have to assume that $\mathrm{F}$ comes in two variants, one with $u \mathrm{Op}$ (movement) and one with an EPP-feature only (base-generation), cf. Alexopoulou (2006: 88) for such an analysis of Greek pu. 
a. Es sind [mee Patiente] choo als (*sie) de Tokter hät chöne behandle. there are more patients come than (them) the doctor has could treat 'There came more patients than the doctor could treat.'

ACC

b. Es sind [mee Lüüt] choo als *(ine) de Tokter there are more people come than (they.DAT) the doctor

hät chöne Medikamänt verschriibe.

DAT

has could medicine prescribe

'There came more people than the doctor could prescribe medicine for.'

Once we go across a sentence boundary, we find the same pattern as with amount relatives: Since the restriction of the degree operator is incompatible with topicality, it will not pass through SpecTopP. Therefore, it can check $u$ Contrast of the intermediate $C$. As a consequence, since long-distance movement is possible, we do not find resumption (as in (19), a silent stage topic, or perhaps the temporal adverbial hüt 'today', occupies SpecTopP in the embedded clause):

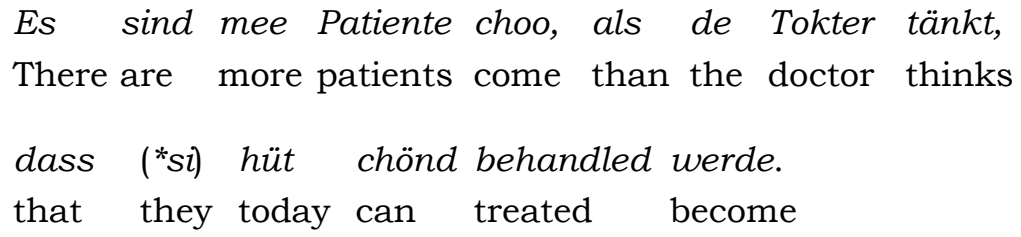

'There came more patients than the doctor thinks can be treated today.'

\subsubsection{Standard German}

While ZG has a means to overcome the incompatibility of the restriction of relative operators with iContrast, viz, resumption, the standard language does not. As a consequence, we expect long-distance relativization to be impossible. This indeed seems to be the case. Though one occasionally finds such examples in textbooks, most speakers reject long-distance relativization (cf. Lühr 1988: 77, Andersson \& Kvam 1984):

(69) a.??Das ist einer der 1 ich glaube, dass $t_{1}$ das schaffen wird.

This is one who.NOM I believe that this manage will

'This is a guy who I think will manage this.'

b.??der Mann, den 1 ich glaube, dass Maria $t_{1}$ liebt

the man who.ACC I believe that Mary loves

'the man who I believe Mary loves'

Since the restriction, which obligatorily bears $i$ Top, cannot value $u$ Contrast of dass, the derivation eventually crashes.

All speakers prefer an alternative construction which involves local extraction in the matrix clause and binding between the relative pronoun and a coreferential pronoun in the dependent clause. This construction was termed RESUMPTIVE PROLEPSIS In Salzmann (2006b):58, 59

58 It is interesting to look at Dutch in this context. Even though long-distance relativization is generally taken to be possible, it nevertheless seems restricted as well. Many speakers prefer alternative constructions similar to the Standard German one in (70). The situation in dialects is particularly 
der Mann, von dem 1 ich glaube, dass Maria ihn $n_{1}$ liebt

the man of who.DAT I believe that Mary him loves

'the man of whom I believe that Mary loves him'

Since the offending element is the intermediate $\mathrm{C}$ dass, we expect long relativization to be possible once the complement lacks dass, as is the case in infinitival complements. This prediction is indeed borne out. To make sure that we are not dealing with a monoclausal structure (where a CP-layer would be absent so that one would be dealing with short whmovement), we deliberately use a non-restructuring predicate:

das Buch, das ich erwartet habe $t_{1} \begin{aligned} & \text { geschenkt } \\ & \text { the book bekmmen } \\ & \text { given which I expected have.1s }\end{aligned}$ to get
'the book I expected to be given as a present'

Since there is no dass, there is no $u$ Contrast that could cause a problem for the movement of the restriction. ${ }^{60} \mathrm{By}$ the same token, we expect long-distance relativization by movement from non-finite clauses in ZG to be possible. This prediction is borne out, a resumptive is not obligatory: 61

$$
\begin{aligned}
& s \quad[\text { Buech], won } i \text { d Susi überredt ha }(s) \text { für mich } z \text { chauffe } \\
& \text { the book C I the Susie convinced have.1SG it for me to buy } \\
& \text { 'the book that I convinced Susie to buy for me' }
\end{aligned}
$$

interesting. The various patterns described in Boef (2008) show that many dialects resort to different means, which may be indicative of extraction difficulties. Barbiers et al. (2005) explicitly suggest that long-distance relativization is impossible in many dialects. To what extent the present analysis can be extended to Dutch is a question we intend to pursue in future work.

59 For reasons that are not clear to us, long-distance relativization appears to have been more acceptable in earlier stages of German (cf. Lühr 1988: 78-79); whether there has been a shift from long-distance relativization to the alternative construction in (70) is not quite clear since they seem to have co-existed for quite some time; cf. Lühr (1988: 79, fn. 24) for discussion.

60 It seems that the restriction on long relativization (and long topic movement more generally) is tied to the finite complementizer dass while non-restructuring infinitives as in (71), which are normally classified as CPs, do not have such a blocking effect. We attribute this to the absence of finiteness, a phenomenon that is widely attested since Chomsky (1973).

61 As indicated in the text, it seems to us that resumptives are often acceptable in non-finite clauses. Hodler (1969: 247) gives such an example:
(i) Usdrück, wo si e rächte Möntsch
schämti
sen $i$ ds Muu z' näh. expressions $\mathrm{C}$ self a decent human.being would.be.ashamed them in the mouth to take 'expressions that a decent human being would be ashamed to use'

If, as proposed in Salzmann (2006b), long-distance relativization in ZG can also be analyzed as an abstract version of the proleptic construction in (70), the possibility of resumption in (i) would be less surprising. It would be parallel to the fact that resumptive prolepsis is also possible with non-finite complements in standard German, cf. Salzmann (2006b: 205). The fact that long-distance movement and the proleptic construction do not block each other implies that they do not compete and thus do not belong to the same reference set. 


\subsection{Why resumption is barred in wh-movement}

Since $Z G$ is a language that makes productive use of resumptives one may wonder what happens under long-distance wh-movement. Like the standard language, ZG employs whoperators that leave behind gaps, resumption is not possible (cf. also Weber 1964: 304):

$$
\begin{array}{ll}
\text { Wem }_{1} \text { mäinsch, dass de Hans } t_{1} /{ }^{*} e m_{1} & \text { ghulffe hät? } \\
\text { who.DAT think that the John } & \text { helped has }
\end{array}
$$

'Who do you think John helped?'

But the question is what happens if an aboutness topic is to be extracted. Can resumptives come to the rescue? The answer is mixed. In principle, wh-movement is incompatible with resumption in ZG and Alemannic more generally. The reason for this is that base-generation requires Case-unmarked operators (cf. Salzmann 2011: 203-208 for additional discussion), but the overt operators found in wh-movement and topicalization are normally Case-marked as e.g. in (73) so that resumption is not an option. There is, however, an alternative construction with whoperators and topics that is compatible with resumption. In this construction, which Salzmann (2006a) termed A'-splits, the operator appears in a Case-unmarked or default nominative form while Case-information is realized in the theta-position by means of resumption (in case of oblique relations additionally governed by a preposition). ZG only distinguishes a direct and an oblique Case (dative), the direct one being used for both subjects and direct objects. The direct Case can be shown to play a double role in that it may also count as Case-unmarked and appear in A'splits with the resumptive realizing nominative/accusative. The first triple illustrates this for whmovement: 62

(74) a. [Wele Maa] $]_{1}$ häsch gsäit, dass $t$ *(en 1$)$ geschter gsee häsch? which man have.2s said that you him yesterday seen have.2s 'Which man did you say that you saw yesterday?'

b. [Wele Maa]1 häsch behauptet, dass $t \quad *\left(e m_{1}\right)$ es Buech ggëë häsch? which man have.2s claimed that you he.DAT a book given have.2s 'To which man did you claim that you had given a book?'

c. [Weli Frau] $]_{1}$ häsch behauptet, dass $t \quad i \quad d$ Schuel bisch mit *(ere 1$)$ ? which woman have.2s claimed that you in the school are with her 'With which woman did you claim that you went to school?'

The following examples illustrate the same point with topicalization (Salzmann 2006b: 376, fn. 297):

a. [Die Frau $]_{1}$ hett $i$ nie tänkt, dass *(si $\left.i_{1}\right)$ mi nett findt. this woman had.SUBJ.1SG I never thought that she me nice finds lit.: 'This woman I would have never thought likes me.'

62 There are no explicit statements about resumption in wh-movement and topicalization in the traditional dialect literature. One does, however, find examples in Weber (1964: 305) and Suter (1976: 186, §319). Crucially, all examples with resumption involve direct relations so that they can all be reanalyzed as A'splits. 
b. [Dää Maa $]_{1}$ glaub i, dass $t \quad *\left(e m_{1}\right)$ nöd wettsch im Tunkle begägne. this man know.1SG I that you he.DAT not would.like.1sg in.the dark meet 'This man I don't know whether I would like to meet in the dark.'

c. [Die Frau] 1 chan I scho verschtaa, dass $t$ mit *(ere 1$)$ wettsch go tanze. this woman can.1SG I certainly understand that you with her want.2SG go dance 'This woman I can certainly understand you would like to go dancing with.'

A'-splits, like resumptive relatives, are insensitive to locality as the following example shows where the resumptive is the complement of a preposition embedded within a PP (Salzmann 2006b: 376, fn. 297):

[Wele Maa] $]_{1}$ häsch gsäit, dass $d<$ mit de Schwöschter von em 1 > which man have.2SG said that you with the sister of he.DAT

$i$ d Schuel bisch?

in the school are

lit.: 'Which man did you say that you went to school with a sister of?'

The derivation of A'-splits is as in (38).

Given the fact mentioned in 6.3 above that gap derivations block resumptive derivations, the apparent optionality between movement and resumption in wh- and topicalization constructions comes as a surprise. Our approach to long-distance movement, however, provides a solution: The intermediate $\mathrm{C}$ differs in movement vs. base-generation to an extent that one can assume that different reference sets are involved. While it has EPP and $u$ Contrast under movement, it lacks such features under base-generation. This difference is not found in local extraction where movement and base-generation are based on the same lexical items and where the functional heads do not differ in their feature specification. ${ }^{63} \mathrm{We}$ can thus avoid the optionality problem because A'-splits do not compete with movement derivations. Long-distance relativization is different, there is no optionality because the movement derivation is ruled out for independent reasons (the topicality of the restriction), only base-generation converges.

We would finally like to note that the syntax of A'-splits can be extended to constructions involving fronted R-pronouns as in the following example:

$D a_{1} \quad k a ̈ n \quad i<k a ̈ n e$, wo öppis de 1 voo verschtaat. $>$

there know I no.one $\mathrm{C}$ something there.of understands

'This issue I don't know anyone who understands.'

Since R-pronouns do not need Case, they can be base-generated directly in the final landing site and be linked to a resumptive (the pronominal part of the pronominal adverb). ${ }^{64}$

63 The only problematic case is the movement of the restriction which we have taken to be triggered by an EPP-feature on Fin $^{\circ}$ in (63). Such a feature will be absent under (local) base-generation. To make the numerations perfectly identical, one would have to assume that movement of the restriction is not feature-driven (perhaps simply repair-driven to allow for amalgamation with Op). For reasons of space we have to leave a full discussion of this issue for a later occasion.

64 There is an optionality problem with R-pronouns, though, that we cannot account for: Next to the splitting construction as in (77), one also finds a pied-piping-like structure. At least in transparent contexts (unlike (77)), both derivations are possible: 


\subsection{Resumption in relativization from V2 complements}

As discussed in 5.2, wh-movement of (sentence) topics from V2-complements is grammatical in standard German and is best analyzed as involving parenthesis. All there is is local extraction so that, as a consequence, no $u$ Contrast is involved that could cause problems for the movement of the restriction. It is therefore interesting to look at the situation in Zurich German relativization. One does find cases of (putative long-distance) relativization into a V2complement. Interestingly, a resumptive is obligatory:

(78) a. vuwäge miim Suh, woni gmeint haa, *(er) seig tod because.of my son $\mathrm{C}$ I thought have he be dead 'because of my son, who I thought was dead'

Stalder (1819: 274)

b. de Maa, woni gsäit han, ich heg *(en) im Tram gsee the man $\mathrm{C}$ I said have.1SG I have.SUBJ him in.the tram seen 'the man that I said I saw in the streetcar'

Since the relative marker $w o(n)$ certainly belongs to the matrix clause, the strings $i$ gmeint haa/i gsäit han would have to be analyzed as a parenthetical. However, neither do such strings ever occur in parenthetical function nor would the remaining sentence be grammatical since relative clauses require verb-final structure, which is incompatible with the V2 order of the complement. As a consequence, such examples do not involve parenthesis. The presence of resumptives shows that movement is not possible; the question is just why. One obvious possibility is to assume that the embedded $\mathrm{C}$ bears an EPP-feature with $u$ Contrast as a subfeature. This would make extraction of the restriction of specific relative operators (which abstract over individuals) impossible, in accordance with (78) (for (78)b one could additionally argue that the embedded SpecCP is occupied so that a topic island blocks extraction). But this predicts that amount relatives should be possible from V2-complements. This prediction is not borne out, amount relativization into a V2-complement is ungrammatical and cannot be saved by resumption:

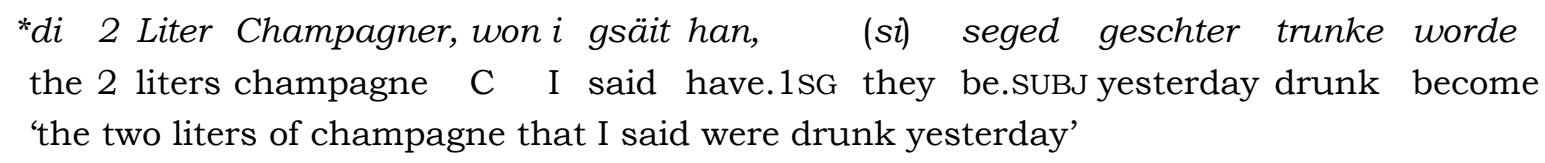

Since resumption is generally incompatible with semantic types other than <e> (Salzmann 2006b), the impossibility of resumption in (79), which involves abstraction over degrees, is actually expected. But the impossibility of movement is surprising if the embedded C involves an EPP-feature. Since long-distance extraction is obviously not an option, it is arguably best to analyze V2-complements as ForcePs whose head cannot attract items for intermediate A'-

(i) Dadevoo ${ }_{1} \quad$ verschtaan i $t_{1}$ nüüt. there.there.of understand.1sg I nothing 'I don't understand anything of it.'

(ii) $D a_{1}$ verschtaan $i$ nü̈t de 1 voo. there understand.1sg I nothing there.of

We leave this for future research. See also Bader \& Bayer (2007) for a treatment of prepositions as exponents of oblique Case; thereby one is no longer forced to say that Case-assignment by prepositions can be suppressed in the context of R-pronouns. 
movement (since V2-clauses are root clauses, the attracted wh-phrase reaches a scope position and is therefore frozen for further A'-movement). Consequently, V2-complements do not allow for long-distance extraction at all. Of course, this fact was documented for wh-movement and topicalization long ago (cf. Müller 2010 for an overview). What is interesting about the ZG facts is that resumption in V2-complements is possible. ${ }^{65}$

Indirectly, these facts can also be taken as evidence in favor of the parenthetical analysis of wh-extraction from V2-complements. Concerning (78), since no long-distance movement dependency is possible with V2-complements and since a parenthetical analysis is ruled out, base-generation is the only option in the case of relativization.

The case can be made even stronger with the observation that relativization into a V2complement is only acceptable if the highest specifier of the embedded complement is filled. Consider the following sentence which is a variant of $(78) \mathrm{b}$ :

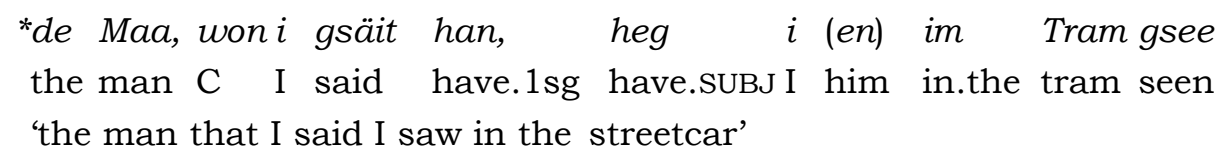

Since no extraction is involved and since a parenthetical analysis is also impossible, the prefield of the embedded V2-complement trivially has to be filled. The same obtains with A'-splits into V2-clauses (recall from above that in A'-splits the operator appears in a default nominative Case form while Case information is realized by the resumptive): SpecForceP has to be filled (we should mention that such examples are marked for most speakers, but the contrast is nevertheless clear):

(81) a. [Wele Maa]1 häsch gsäit, de Hans heg *(eml) geschter ghulffe? which man have.2SG said the John has.SUBJ he.DAT yesterday helped 'Which man did you say John helped yesterday?'

b. *[Wele Maa $]_{1}$ häsch gsäit, heg $\left(e m_{1}\right)$ de Hans geschter ghulffe? which man have.2SG said has.SUBJ he.DAT the John yesterday helped 'Which man did you say John helped yesterday?'

65 An alternative explanation for the opacity of V2-complements can be found in the following observation that embedded wh-sentences are incompatible with V2:

(i) Ich möchte wissen, *wohin ist Susi gefahren/ wohin Susi gefahren ist. I would.like know where is Susi driven where Susi driven is 'I would like to know where Susi drove to.'

A possibility to unify the island nature of V2-complements with the data in (i) is to follow Heck (2010) in assuming that V2-complements are adjoined to VP. According to Heck, the impossibility of embedded wh$\mathrm{V} 2$ as in (i) could then follow from the fact that the matrix predicate does not c-command the embedded $\mathrm{C}$ (since normal V2-complement satisfy a theta-role of the matrix verb, special provisions have to be made for theta-role assignment, e.g. as in Fanselow 2001). For a very different explanation of the long extraction restriction from V2-complements, cf. Müller (2010). 
The ungrammaticality of (81)b can be explained as follows: A parenthetical analysis is theoretically possible since häsch gsäit can occur as a parenthetical and the wh-operator is compatible with a V2-clause. This implies that $(81) \mathrm{b}$ would only involve short extraction. However, A'-splits are independently impossible in local wh-movement:

$$
\begin{aligned}
& \text { *[Wele Maa }]_{i} \text { häsch emi geschter ghulffe? } \\
& \text { which man have.2SG he.DAT yesterday helped } \\
& \text { 'Which man did you help yesterday?' }
\end{aligned}
$$

The reason for this is simple: Since a movement derivation is possible in this context, it will block the A'-split/resumptive derivation - as in the relativization of local subjects/direct objects (cf. 6.3). Since a parenthetical analysis (with local extraction) is blocked by economy (81)b, the only remaining possibility involves a real V2-complement. However, since long-distance extraction is not possible from V2-complements, base-generation remains as the sole option. In that case, however, SpecForceP has to be filled, since V2 clauses require the highest specifier to be overt. Consequently, only the version with a filled specifier is grammatical, (81)a.

\section{Conclusion}

In this article we have argued in favor of a new perspective on that-trace effects. We have shown that that-trace effects are not peculiar to subjects, but obtain more generally if a sentence/aboutness topic undergoes long-distance extraction. Since in English, the subject usually coincides with the topic, that-trace effects appear to be subject-related. Data from German, however, show that similar effects obtain with non-subjects that are extracted from the highest position in the middle field. The fact that that-trace effects are much less visible in German can be related to the greater flexibility of the German clause: Since it arguably does not have a fixed subject position, but just a high topic position, other elements than the subject can occupy the topic position thereby making extraction of the subject from a lower position possible. In this case, the subject does not figure as the aboutness topic, and it can undergo long-distance movement. The impossibility of long-distance movement of sentence topics was subsumed under an independently established constraint barring long-distance movement of non-contrastable elements; this we took to be due to a feature $u$ Contrast located on the intermediate complementizer dass. The concrete implementation involves the following ingredients: Operator and restriction are taken to be independent syntactic objects that undergo independent checking operations and that have to amalgamated under adjacency at PF. While Op is directly merged in the matrix scope position (ForceP), the restriction originates in the argument position and moves into the matrix clause to amalgamate with Op. The degradedness of long-topic movement then comes from the fact that the intermediate $\mathrm{C}$ endowed with an edge/EPP-feature is taken to involve a feature $u$ Contrast as a subfeature. $u$ Contrast is incompatible with topical elements. Whenever a topical element - in our case the restriction functioning as the sentence topic of the embedded clause - moves via SpecCP, it will fail to check $u$ Contrast of $\mathrm{C}$ and the derivation crashes. Extraction is possible once some other element functions as the sentence topic and the restriction can bear iContrast. Extraction of amount phrases provides independent evidence for this approach: Since their restriction is inherently non-topical, there will be no movement via TopP; the restriction can bear iContrast, value the corresponding feature on the intermediate $\mathrm{C}$ and move into the matrix clause to amalgamate with Op.

In the final part of the article we showed that our approach to long-distance movement has wider coverage. It accounts for a hitherto puzzling fact about Zurich German relativization: While subjects and direct objects are relativized by means of movement in local relativization, they 
require resumptives as soon as a sentence boundary is crossed. Since resumptives normally occur only as a last resort when gap derivations fail, long-distance relativization by movement must be ungrammatical. We have linked this to the topical nature of the restriction of relative operators that makes them incompatible with $u$ Contrast on the embedded $\mathrm{C}$. As opposed to the standard language, ZG can resort to an alternative mechanism to establish the A'-dependency, viz. resumption where the restriction is realized by an independent elment and therefore does not have to undergo movement into the matrix clause for purposes of amalgamation. While resumption is a well-known repair strategy to bridge opaque syntactic domains like islands, the case we are documenting here is remarkable because resumption/base-generation serves to avoid an information structural conflict: Since under base-generation intermediate Cs do not have any attracting features, $u$ Contrast is automatically missing as well. Consequently, there is no risk of there being an unvalued $u$ Contrast. Thus, the derivation converges. 


\section{$\underline{\text { Acknowledgments }}$}

Parts of this work have been presented over the years at various conferences and workshops by the authors individually but also jointly, most notably at the repair workshop at the DGfS 2009 in Osnabrück (February 2009) and at the Swiss Workshop in Generative Grammar (SWIGG), Neuchâtel (April 2009). We wish to thank the respective audiences for discussion. We have benefited from discussions with Markus Bader, Ellen Brandner, Peter Culicover, Nomi ErteschikShir, Marcel den Dikken, Werner Frey, Alessandra Giorgi, Jane Grimshaw, Jana Häussler, Uli Lutz, Amanda Pounder, Ur Shlonsky, Luigi Rizzi, Yvonne Viesel. None of them must be held responsible for any shortcomings of our analysis. Comments by Patrick Brandt and an anonymous reviewer helped us greatly to improve the quality and readability of this article. Thanks to Annika Nitschke for editorial help. For support of this research we thank the former Konstanz SFB 471 and the Swiss National Science Foundation (grant nr. PBSK-1--119747/1).

\section{References}

Ackema, Peter 2010 Restrictions on subject extraction: a PF interface account. In: Raffaella Folli and Christiane Ullbrich (eds.), Interfaces in Linguistics. New Research Perspectives, 225-241. Oxford: Oxford University Press.

Ackema, Peter and Ad Neeleman 2004 Beyond Morphology. Oxford: Oxford University Press.

Alexopoulou, Theodora 2006 Resumption in Relative Clauses. Natural Language and Linguistic Theory 24: 57-111.

Andersson, Sven-Gunnar and Sigmund Kvam 1984 Satzverschränkung im heutigen Deutsch. Eine syntaktische und funktionale Studie unter Berücksichtigung alternativer Konstruktionen. Tübingen: Gunter Narr (= Studien zur deutschen Grammatik 24).

Aoun, Yoseph, Lina Choueiri and Norbert Hornstein 2001 Resumption, Movement, and Derivational Economy. Linguistic Inquiry 32/3: 371-403.

Barbiers, Sjef, Hans Bennis, Magda Devos, Gunther de Vogelaer, and Margreet van der Ham 2005 Syntactic Atlas of the Dutch Dialects, Volume 1. Amsterdam: Amsterdam University Press.

Bayer, Josef 1984 Comp in Bavarian syntax. The Linguistic Review 3: 209-274.

Bayer, Josef 2001 Asymmetry in emphatic topicalization. In: Caroline Féry and Wolfgang Sternefeld (eds.), Audiatur Vox Sapientiae, 15-47. Berlin: Akademie-Verlag.

Bayer, Josef 2005 Was beschränkt die Extraktion? Subjekt - Objekt vs. Topic - fokus. In: Franz Josef D'Avis (eds.), Deutsche Syntax: Empirie und Theorie, 233-257. Göteborg: Acta Universitatis Gothoburgensis.

Bayer, Josef (to appear) From modal particle to interrogative marker: a study of German denn. In: Laura Brugè, Anna Cardinaletti, Giuliana Giusti, Nicola Munaro and Cecilia Poletto (eds.), Functional Heads. Oxford: Oxford University Press. 
Bayer, Josef and Peter Suchsland 1998 Some remarks on expletives in German. Paper for Noam Chomsky on his 70th birthday. Electronically available via the MIT Press websidehttp://mitpress.mit.edu/celebration.

Bayer, Josef, Markus Bader and Michael Meng 2001 Morphological underspecification meets oblique Case: syntactic and processing effects in German. Lingua 111: 465-514.

Bayer, Josef and Markus Bader 2007 On the syntax of prepositional phrases. In: Andreas Späth (ed.), Interface and Interface Conditions, 157-179. Berlin: Mouton de Gruyter.

Behaghel, Otto 1932 Deutsche Syntax. Eine geschichtliche Darstellung, Vol. 4. Heidelberg: Winter. Bennis, Hans 1986 Gaps and Dummies. Dordrecht: Foris.

Bhatt, Rakesh Mohan 1999 Verb Movement and the Syntax of Kashmiri. Dordrecht: Kluwer.

Bianchi, Valentina 2004 Resumptive relatives and LF chains. In: Luigi Rizzi (ed.), The Cartography of Syntactic Structures, 76-114. Oxford: Oxford University Press.

Boeckx, Cedric 2003 Islands and Chains. Resumption as Stranding. Amsterdam u.a.: John Benjamins.

Boef, Eefje 2008 Long-distance relativization in varieties of Dutch. MA Thesis, University of Utrecht.

Bresnan, Joan 1977 Variables in the theory of transformations. In: Peter Culicover, Tom Wasow, and Adrian Akmajian (eds.), Formal Syntax, 157-196. New York: Academic Press.

Bresnan, Joan 1994 Locative inversion and the architecture of Universal Grammar. Language 70: $72-131$.

Bresnan, Joan and Sam Mchombo 1987 Topic, pronoun, and agreement in Chichewaa. Language 63: 741-782.

Bruening, Benjamin 2010 Language-particular syntactic rules and constraints: English locative inversion and do-support. Language 86: 43-84.

Cardinaletti Anna 2004 Toward a cartography of subject positions. In: Luigi Rizzi (ed.), The Structure of CP and IP. The Cartography of Syntactic Structures, Volume 2, 115-165. New York: Oxford University Press.

Chao, Wynn and Peter Sells 1983 On the interpretation of resumptive pronouns. Proceedings of the North East Linguistic Society 13: 47-61.

Carlson, Gregory 1977 Reference to Kinds in English. Ph.D. Dissertation, University of Massachusetts, Amherst.

Chomsky, Noam 1973 Conditions on transformations. In: Stephen R. Anderson and Paul Kiparsky (eds.), A Festschrift for Morris Halle, 232-286. New York: Holt, Rinehart and Winston.

Chomsky, Noam 1981 Lectures on Government and Binding. Dordrecht: Foris.

Chomsky, Noam 1986 Barriers. Cambridge, Massachusetts: MIT-Press.

Chomsky, Noam and Howard Lasnik 1977 Filters and control. Linguistic Inquiry 8: 425-504. 
Chung, Sandra and Jim McCloskey 1983 On the interpretation of certain island effects in GPSG. Linguistic Inquiry 14: 704-713.

Cowart, Wayne 1997 Experimental Syntax. Applying Objective Methods to Sentence Judgements. Thousand Oaks u.a.: SAGE.

Culicover, Peter W. 1993 Evidence against ECP accounts of the that-trace effect. Linguistic Inquiry 14: 704-713.

Demirdache, Hamida 1991 Resumptive Chains in Restrictive Relatives, Appositives and Dislocation Structures. Doctoral Dissertation, Massechusetts Institut of Technology.

Dikken, Marcel den 2007 Questionnaire study on Dutch that-trace effects: Stimuli and results. Ms. City University of New York.

Endriss, Cornelia and Stefan Hinterwimmer 2008 Direct and indirect aboutness topics. Acta Linguistica Hungarica 55/3-4: 297-307.

Erteschik-Shir, Nomi 1997 The Dynamics of Focus Structure. Cambridge: Cambridge University Press.

Erteschik-Shir, Nomi 1999 Focus structure and scope. In: Georges Rebuschi and Laurie Tuller (eds.), The Grammar of Focus, 119-150. Amsterdam: Benjamins.

Erteschik-Shir, Nomi 2009 Canonical information structures. Lecture at Harvard University, 8 May, 2009. http://www.bgu.ac.il/ shir/harvard\%208\%20may\%202009.pdf.

Fanselow, Gisbert 1987 Konfigurationalität: Untersuchungen zur Universalgrammatik am Beispiel des Deutschen. Tübingen: Narr.

Fanselow, Gisbert 2001 Features, theta-Roles, and free Constituent Order. Linguistic Inquiry 32: 405-437.

Fanselow, Gisbert 2002 Quirky "subjects" and other specifiers. In: Ingrid Kaufmann and Barbara Stiebels (eds.), More than Words: a Festschrift for Dieter Wunderlich, 227-250. Berlin: Akademie Verlag.

Fanselow, Gisbert and Denisa Lenertová 2011 Left peripheral focus: Mismatches between syntax and information structure. Natural Language and Linguistic Theory 29: 169-209.

Featherston, Sam 2005 That-trace in German. Lingua 1091: 1-26.

Frey, Werner 2004 A medial topic position for German. Linguistische Berichte 198: 153-190.

Frey, Werner 2005 Zur Syntax der linken Peripherie im Deutschen. In: Franz-Josef d'Avis (ed.), Deutsche Syntax: Empirie und Theorie, 147-171. Göteburg: Göteborger Germanistische Forschungen 46.

Frey, Werner 2006 How to get an object-es into the German prefield. In: Patrick Brandt and Eric Fuß (eds.), Form, Structure, and Grammar. A Festschrift Presented to Günther Grewendorf on Occasion of his 60th Birthday, 337-352. Berlin: Akademie.

Gazdar, Gerald 1981 Unbounded dependencies and coordinate structure. Linguistic Inquiry 12: $155-184$.

Grewendorf, Günther 1988 Aspekte der deutschen Syntax. Eine Rektions-Bindungs-Analyse. Tübingen: Narr.

Grimshaw, Jane 1997 Projection, heads, and optimality. Linguistic Inquiry 28: 373-422. 
Guilliot, Nicolas and Nouman Malkawi 2006 When resumption determines reconstruction. Proceedings of the West Coast Conference on Formal Linguistics 25: 168-176.

Gundel, Jeanette K. 1974 The Role of Topic and Comment in Linguistic Theory. Ph.D. dissertation, University of Texas.

Gundel, Jeanette K. 1999 Topic, focus and the grammar pragmatics interface. In: Jim Alexander, Na-Rae Han and Michelle Minnick (eds.), Proceedings of the 23rd Annual Penn Linguistics Colloquium. Penn Working Papers in Linguistics, 185-200. Philadelphia: University of Pennsylvania Press.

Haider, Hubert 1983 Connectedness effects in German. Groninger Arbeiten zur Germanistischen Linguistik 23: 83-119.

Haider, Hubert 2000 OV is more basic than VO. In: Peter Svenonius (ed.), The Derivation of VO and $O V, 45-67$. Amsterdam: Benjamins.

Haider, Hubert 2004 The superiority conspiracy: four constraints and a processing effect. In: Anton Stepanov, Gisbert Fanselow and Ralf Vogel (eds.), Minimality Effects in Syntax, 147-175. Berlin: Mouton de Gruyter.

Hartmann, Jutta M. 2008 Expletives in Existentials: English there and German da. Utrecht: LOT. Heck, Fabian 2010 A Constraint on recursion. Handout, DGfS 2010, Berlin.

Heim, Irene 1982 The Semantics of Definite and Indefinite Noun Phrases. PhD dissertation, University of Massachusetts.

Hodler, Werner 1969 Berndeutsche Syntax. Bern: Francke Verlag.

Kandybowicz, Jason 2006 Comp-trace effects explained away. Proceedings of the West Coast Conference on Formal Linguistics 25: 220-228.

Keenan, Edward L. and Bernard Comrie 1977 Noun phrase accessibility and Universal Grammar. Linguistic Inquiry 8: 63-99.

Kiss, Katalin E. 2002 The EPP in a topic-prominent language. In Peter Svenonius (eds.). Subjects, Expletives, and the EPP, 107-124. Oxford: Oxford University Press.

Kiziak Tanja 2007 Long extraction or parenthetical insertion? Evidence from judgement studies. In: Nicole Dehé and Yordanka Kavalova (eds.), Parentheticals, 121-144. Amsterdam: John Benjamins.

Kiziak, Tanja 2010 Extraction Asymmetries: Experimental Evidence from German. Amsterdam: John Benjamins.

Koster, Jan 2003 All languages are tense-second. In Jan Koster and Henk van Riemsdijk (eds.), Germania et Alia: A Linguistic Webschrift for Hans den Besten, http://www.let.rug.nl/koster/DenBesten/contents.htm.

Krifka, Manfred 2008a What do Contrastive Topics and Frame Setters have in Common? The Role of Addressing and Delimitation in Information Structure. Presentation given at the conference on 'Contrastive Information Structure Analysis', University of Wuppertal, March 18-19, 2008. 
Krifka, Manfred 2008b Basic notions of information structure. Acta Linguistica Hungarica 55: 243-276.

Lambrecht, Knud 1994 Information Structure and Sentence Form: Topic, Focus, and the Mental Representation of Discourse Referents. New York: Cambridge University Press.

Lühr, Rosemarie 1988 Zur Satzverschränkung im heutigen Deutsch. Groninger Arbeiten zur Germanistischen Linguistik 29: 74-87.

Lutz, Ulrich 1997 Parasitic gaps und Vorfeldstruktur. In: Franz-Josef d'Avis and Ulrich Lutz (eds.), Zur Satzstruktur des Deutschen, 55-80. Tübingen: Arbeitspapiere des Sonderforschungsbereichs 340 .

Mayr, Clemens 2010 On the necessity of phi-features: The case of Bavarian subject extraction. In Phoevos Panagiotidis (ed.), The Complementizer Phase: Subjects and WhDependencies, 117-142. Oxford: Oxford University Press.

Meinunger, André 2000 Syntactic aspects of Topic and Comment. Amsterdam: John Benjamins.

Meinunger, Andre 2006 Interface Restrictions on Verb Second. The Linguistic Review 23: 127-160. Müller, Gereon 1995 A-bar Syntax: a Study in Movement Types. Berlin: Mouton de Gruyter.

Müller, Gereon 2010 Movement from Verb-Second Clauses Revisited. In: Thomas Hanneforth and Gisbert Fanselow (eds.), Language and Logos. A Festschrift for Peter Staudacher, 97-128. Berlin: Akademieverlag.

Müller, Gereon 2012 A Local Reformulation of the Williams Cycle. Ms. University of Leipzig.

Müller, Gereon and Wolfgang Sternefeld 1993 Improper Movement and Unambiguous Binding. Linguistic Inquiry 24: 461-507.

Penka, Doris 2007 Negative Indefinites. Ph.D. Dissertation, University of Tübingen:

Pesetsky, David 1998 Some Optimality Principles of Sentence Pronunciation. In: Pilar Barbosa, Danny Fox, Martha McGinnis and David Pesetsky (eds.), Is the Best Good Enough? Optimality and Competition in Syntax, 337-383. Cambridge: MIT Press.

Pesetsky, David Michael and Esther Torrego 2001 T-to-C Movement: Causes and Consequences. In: Michael Kenstowicz (ed), Ken Hale: A Life in Language, 355-426. Cambridge: MIT Press.

Reinhart, Tanya 1981 Pragmatics and linguistics: an analysis of sentence topics. Philosophica 27: 53-94.

Reis, Marga 1995 Extractions from Verb-Second clauses in German? In: Ulrich Lutz and Jürgen Pafel (eds.), On extraction and extraposition in German, 45-88. Amsterdam: John Benjamins.

Rezac, Milan 2004 Elements of Cyclic Syntax: Agree and Merge. Doctoral Dissertation, Department of Linguistics, University of Toronto. 
Riemsdijk, Henk van 1989 Swiss Relatives. In: Dany Jaspers, Wim Klooster, Yvan Putseys \& Pieter Seuren (eds), Sentential Complementation and the Lexicon, 343-354. Studies in Honour of Wim de Geest. Foris: Berlin.

Riemsdijk, Henk van2008 Identity Avoidance: OCP effects in Swiss relatives. In Robert Freidin, Carlos P. Otero and Maria Luisa Zubizarreta (eds.), Foundational Issues in Linguistic Theory. Essays in Honor of Jean-Roger Vergnaud, 227-250. Cambridge, Massechusetts: MIT Press.

Rizzi, Luigi 1990 Relativized Minimality. Cambridge, Massachusetts: MIT Press.

Rizzi, Luigi 1997 The Fine Structure of the Left Periphery. In: Liliane Haegeman (ed.), Elements of Grammar, 281-337. Dordrecht: Kluwer.

Rizzi, Luigi 2001 Reconstrution, Weak Island Sensitivity, and Agreement. In: Carlo Cechetto. Gennaro Chierchia and Maria Teresa Guasti (eds.), Semantic Interfaces, 145-176. Stanford: CSLI.

Rizzi, Luigi and Ur Shlonsky 2006 Satisfying the Subject Criterion by a non subject: English Locative Inversion and Heavy NP Shift. In: Mara Frascarelli Mara (ed.), Phases of interpretatio,. 341-361. Berlin: de Gruyter,.

Rizzi, Luigi and Ur Shlonsky 2007 Strategies of subject extraction. In: Hans-Martin Gärtner and Uli Sauerland (eds.), Interfaces + Recursion = Language?, 115-160. Berlin: Mouton de Gruyter.

Ross, John Robert1973 Slifting. In: Maurice Gross and Marcel Schützenberger (eds.), Formal analysis of natural languages, 133-172. Mouton and Company: The Hague.

Salzmann, Martin 2006a Resumptive Pronouns and Matching Effects in Zurich German Relative Clauses as Distributed Deletion. In: Noureddine Elouazizi, Frank Landsbergen, Maika Poss \& Martin Salzmann (eds.): Leiden Papers in Linguistics 3.1, 17-50.

Salzmann, Martin 2006b Resumptive Prolepsis. A Study in indirect A'-dependencies. LOT: Utrecht. www.lotpublications.nl/publish/articles/001910/bookpart.pdf.

Salzmann, Martin 2008 Variation in resumption requires violable constraints - A case study in Alemannic relativization. In: Hans Broekhuis and Ralf Vogel (eds.), Optimality Theory and Minimalism: Interface Theories, 99-132. www.ling.uni-potsdam.de/lip.

Salzmann, Martin 2009a When movement and base-generation compete - on the definition of the reference set, the typology of resumption, and ranked economy constraints. Groninger Arbeiten zur Germanistischen Linguistik 48, 27-63. http:/ /gagl.eldoc.ub.rug.nl.

Salzmann, Martin 2009b Different notions of variation and their reflexes in Swiss German relativization. In: Andreas Dufter, Jürg Fleischer and Guido Seiler (eds.), Describing and Modeling Variation in Grammar, 135-161. Berlin/New York: Mouton de Gruyter.

Salzmann, Martin 2009c When movement and base-generation compete. The definition of the reference set and parameterized preferences for elementary operations. Linguistics in the Netherlands 2009: 64-77.

Salzmann, Martin 2011 Silent resumptives in Zurich German possessor relativization. In Peter Gallmann \& Melanie Wratil (eds.), Null Pronouns, 141-221. Berlin: Mouton de Gruyter. 
Salzmann, Martin (to appear) On three types of variation in resumption - evidence in favor of violable and ranked constraints. In: Hans Broekhuis and Ralf Vogel (eds), Linguistic Derivations and Filtering. Equinox.

Salzmann, Martin and Guido Seiler 2010 Variation as the exception or the rule? Swiss relatives, revisited. Sprachwissenschaft 35: 79-117.

Salzmann, Martin, Jana Häussler, Markus Bader and Josef Bayer (to appear) That-trace effects without traces. An experimental investigation. Proceedings of the 42nd Annual Meeting of the North East Linguistik Society.

Stalder, Franz Joseph 1819 Die Landessprachen der Schweiz oder schweizerische Dialektologie. Sauerländer: Aarau.

Steinbach, Markus 2007 Integrated parentheticals and assertional complements. In: Nicole Dehé and Yordanka Kavalova (eds.), Parentheticals, 53-87. Amsterdam: John Benjamins.

Strawson, Peter F. 1964 Identifying reference and truth values. Theoria 3: 96-118.

Suter, Rudolf 1992 Baseldeutsch-Grammatik. Basel: Merian.

Viesel, Yvonne 2011 Glaubt er, glaub ich, glaub. Integrierte V1-Parenthesen, Extraktion aus V2.Komplementen, Grammatikalisierung. Linguistische Berichte 226: 130-169.

Weber, Albert 1964 Zürichdeutsche Grammatik: Ein Wegweiser zur Guten Mundart. Schweizer. Zürich: Spiegel Verlag. 